\title{
La presidencia de los Estados Unidos ¿Un modelo de poder ejecutivo?
}

\author{
DAVID ORTIZ JR \\ UNIVERSIDAD DE ARIZONA
}

\section{RESUMEN}

Este articulo identifica, en seis secciones, los estructuras fundamentales del sistema presidencial de los Estados Unidos y sostiene que la esencia de la posición del presidente en el sistema político, le viene de las variadas atribuciones establecidas constitucionalmente y la práctica

creada históricamente por el ejercicio de los diferentes presidentes. Atribuye mucho del poder y la autoridad presidencial al contexto histórico en que los

fundadores de la Constitución

Americana crearon la institución, incluyendo sus poderes y límites. La primera sección discurre sobre las numerosas atribuciones del presidente y el ejercicio práctico de

las mismas para llevar a cabo la política del Ejecutivo con éxito. La sección segunda examina el proceso histórico de la creación de

la Presidencia norteamericana y subraya la íntima relación entre el nuevo sistema de gobierno, la nueva nación surgida tras la independencia, y las circunstancias que rodearon su nacimiento. $\mathrm{La}$ sección tercera hace un repaso de las tres ramas independientes del gobierno de los EEUU y revela sU interdependencia para conseguir un

gobierno equilibrado. La sección cuarta esboza los límites del poder

\section{ABSTRACT}

This article identifies, in six sections, the basic structures of the American Presidential system of government and asserts that the nature of the office springs from the various roles the president is called upon to play in the execution of the duties of office and the historical record of the previous office holders. It attributes much of the president's power and authority to the historical context in which the framers of the American Constitution created the position, including its powers and limits. The first section discusses the multiple roles the president plays while in office and notes that these roles must be performed seamlessly in order for America's chief executive to be successful. Section two examines the historical background of the creation of the position and emphasizes the connection between the fledgling government, the new nation, and the historical circumstances surrounding its birth. The third section reviews the three independent branches of United States' government and reveals their interdependence in an effort to produce balanced government, which results in a system of reciprocal function. The fourth section outlines the limits of presidential power and authority. It describes the president's facilitative 
y la autoridad presidencial. Describe los poderes más sutiles del presidente, al lado de sus poderes efectivos en un contexto de enfrentamiento entre los poderes Ejecutivo y Legislativo. Esta sección también ofrece una breve sinopsis de los presidentes que más influyeron en el desarrollo del poder presidencial por vía de su autoridad personal. La sección penúltima esboza algunas de las diferencias básicas entre sistemas presidenciales y parlamentarios, $y$ ofrece algunas razones para explicar la difícil exportación exitosa del sistema presidencial norteamericano. Finalmente, la conclusión es un breve análisis personal de la presidencia en la actualidad, y sugiere temas para ulteriores análisis o aportaciones al desarrollo de la naturaleza representativa del gobierno presidencial norteamericano.

PALABRAS CLAVE Historia de EE.UU., historia contemporánea, constitucionalismo, liberalismo, sistema electoral. power versus his personal authority in a context of contested power, especially with regard to the Congress. This section also provides a brief synopsis of the most influential U.S. presidents in terms of their expansion of presidential power via their personal authority. The penultimate section sketches some of the basic differences between presidential and parliamentary systems and suggests reasons for the lack of portability of presidential systems. The conclusion briefly summarizes my own view of the presidency as it currently stands and suggests areas for further discussion, if not improvement, of the representative nature of American presidential government.

KEYS WORDS

U.S. history, contemporary history, constitutionalism, liberalism, electoral system. 


\section{INTRODUCCIÓN'}

Quizá no haya otro cargo político en el planeta Tierra que acarree tanto poder y tanta atención como la Presidencia de los Estados Unidos de América. No hay ningún otro dirigente político en el mundo tan escrutado, criticado, ridiculizado, ensalzado, injuriado, como el presidente de EE.UU., ni al que tantos atribuyan tanto fuera del control de uno solo. Se trata de un puesto con una responsabilidad fuera de lo común. Su naturaleza es resultado, en parte, del poso histórico de las pasadas acciones presidenciales, pero también de la simultaneidad de funciones que desempeña un presidente en cuanto accede al cargo. La evolución de la presidencia ha supuesto, cada vez más, el cumplimiento de un conjunto de tareas muy diferentes ${ }^{2}$. Para desempeñar el cargo con éxito, un presidente no sólo debe estar preparado para llevar a cabo todas esas tareas sin solución de continuidad, sino que debe parecer capaz de hacerlo, igual que un buen actor va asumiendo el carácter y el comportamiento de cada nuevo papel que ha de representar. Si bien estas funciones presidenciales ya estaban presentes desde el comienzo de la institución, el peso creciente de cada una de ellas, y el tiempo cada

' Este trabajo ha sido posible gracias al Proyecto de Investigación 06/0069/2002 de la Comunidad de Madrid. En este artículo me he inspirado muy especialmente en las opiniones expresadas en los siguientes trabajos sobre la Presidencia de los EE.UU. De ellos he extraído citas, he copiado modelos, y he modificado ligeramente las interpretaciones originales alli reflejadas. Lo que sigue no es una lista exhaustiva, sino una bibliografía selecta de textos que he considerado particularmente útiles para formular mis propias ideas acerca de la naturaleza de la Presidencia: G.H. BENNETT, The American Presidency 1945-2000: Illusions of Grandeur, Phoenix Mill, UK: Sutton Publishing Limited, 2000; Lonnie S. Bunch III, Spencer R. Crew, Mark G. Hirsch, Harry R. RuBENSTEIN, The American Presidency: A Glorious Burden, Washington, D.C.: Smithsonian Institution Press, 2000; Christopher and James Lincoln Collier, Decision in Philadelphia: The Constitutional Convention of 1787, New York: Random House, 1986; Byron S. Daynes and Glen Sussman, The American Presidency and the Social Agenda, Upper Saddle River, NJ: Prentice Hall, Inc., 2001; Michael A. Genovese, The Power of the American Presidency 1789-2000, New York: Oxford University Press, 2001; Gary L. Gregg II, The Presidential Republic: Executive Representation and Deliberative Democracy, Lanham, MD: Rowman and Littlefield Publishers, 1997; Ernest S. Griffith, The American Presidency: The Dilemmas of Shared Power and Divided Government, New York: New York University Press, 1976; Arend Lijphart, Democracy in Plural Societies, New Haven, CT: Yale University Press, 1977; Arend Lijphart, Democracies: Patterns of Majoritarian and Consensus Government in TwentyOne Countries, New Haven, CT: Yale University Press, 1984; Arend Lijphart, edit., Parliamentary versus Presidential Government, New York: Oxford University Press, 1992; Scott Mainwaring, «Presidentialism in Brazil: The Impact of Strong Constitutional Powers, Weak Partisan Powers, and Robust Federalism", N. 9 225, The Latin American Program Working Paper Series, Woodrow Wilson International Center for Scholars, March 1997; Kurt von Mettenheim, edit., Presidential Institutions and Democratic Politics: Comparing Regional and National Contexts, Baltimore: The Johns Hopkins University Press, 1997; William B. Michaelsen, Creating the American Presidency 1775-1789, Lanham,MD: University Press of America, 1987; Michael P. Riccards, The Ferocious Engine of Democracy: A History of the American Presidency, vol. 1, From the Origins through William McKinley, Foreword by Herbert Mitgang, Lanham, MD: Madison Books, 1995; William J. Ridings, Jr. and Stuart B. Mclver, Rating the Presidents: A Ranking of the U.S. Leaders, from the Great and honorable to the Dishonest and Incompetent, Secaucus, NJ: Carol Publishing Group, 1997; Charles C. Thach, Jr., The Creation of the Presidency 1775-1789: A Study in Constitutional History, Ph.D. Dissertation, Baltimore, MD: The Johns Hopkins Press, 1923; Gordon S. Wood, The Creation of the American Republic 1776-1787, Chapel Hill: University of North Carolina Press, 1969.

${ }^{2}$ Mi exposición acerca de las funciones del Presidente sigue el modelo encontrado en Bunch, et al, The American Presidency: A Glorious Burden, 67-89. 
vez mayor que cada una de ellas consume, han aumentado enormemente la carga que supone ser presidente. Seguidamente haré una breve sinopsis de las funciones presidenciales.

La primera función enumerada en el juramento presidencial es la de comandante en jefe. Ninguna otra de las funciones presidenciales le aporta tanto poder y, al mismo tiempo, tantas restricciones al cargo como el papel de comandante en jefe. Como su nombre implica, el Presidente es el dirigente de todas las fuerzas armadas de los EE.UU., incluyendo el vasto arsenal nuclear del país. El Presidente puede ordenar a las fuerzas militares de los EE.UU. que ataquen, si bien su poder en este sentido está limitado constitucionalmente, porque debe pedir al Congreso que declare la guerra antes de poner en marcha la maquinaria militar del país. Los presidentes norteamericanos han solventado esta restricción impuesta por la Constitución mediante el uso de resoluciones $u$ órdenes del ejecutivo para llevar a cabo acciones militares rápidas, evitando así prolongados debates en el Congreso acerca de una declaración de guerra. Muy recientemente, George W. Bush ha usado, algunos dirían que ha abusado, de esta autoridad a fin de llevar a cabo la guerra y ocupación de Iraq. De hecho, no ha habido ningún presidente desde la Segunda Guerra Mundial que haya obtenido una declaración oficial de guerra por parte del Congreso. Las guerras de Vietnam, Granada, Golfo Pérsico, Afganistán, y ahora Iraq, todas se realizaron mediante la vía de la resolución presidencial, sin que mediara declaración de guerra oficial. Claramente pues, el poder del Presidente en tanto que comandante en jefe se ha ampliado de una manera que los Padres de la Constitución desaprobarían, sobre todo teniendo en cuenta que los sucesivos presidentes se las han arreglado para evadir el control constitucional que ellos establecieron a fin de evitar que una sola persona tuviera tanto poder en sus manos.

El Presidente también es el jefe del poder ejecutivo del país. Es éste el elemento administrativo de la Presidencia: el Presidente debe supervisar la correcta aplicación de las leyes. El Presidente también nombra a los funcionarios del estado, contando para ello con el asesoramiento y la aprobación del Congreso. A veces, esta tarea es más difícil de lo que parece, especialmente cuando la mayoría en el Congreso no pertenece al partido político del presidente de turno. En tales casos, muchos nombramientos se convierten en verdaderas batallas políticas, sobre todo tratándose de nombramientos judiciales. El Presidente también es la cúspide de una hoy vasta burocracia, que ha crecido vertiginosamente desde los primeros días de la institución. La Administración norteamericana es actualmente más grande de lo que los Padres constitucionales hubieran podido imaginar jamás, y el Presidente, como cabeza de la misma, tiene capacidad para influir en el Estado en una variedad enorme de formas que no estuvieron a disposición de anteriores jefes del ejecutivo.

Otra responsabilidad presidencial, otro elemento típico del cargo, consiste en ostentar la más alta diplomacia del país. El Presidente se constituye en 
el representante nacional y único del país en el escenario global. EE.UU. es un país fundado y poblado por inmigrantes. Como tal, mantiene lazos culturales con todo el resto de naciones de la Tierra. El Presidente es pues el embajador del país en el mundo, y representa los intereses y las aspiraciones de las diversas comunidades de inmigrantes, tanto en el interior como en el extranjero cuando se reúne con otros líderes mundiales. Por supuesto, se espera del Presidente que defienda los intereses políticos y económicos de los EE.UU., tanto dentro como fuera del país. También se espera del Presidente que sea el portavoz y el promotor de los principios democráticos universales y de los derechos humanos. El Presidente es, pues, un líder tanto nacional como mundial. Esta función le confiere una gran autoridad para diseñar y dar forma a la política exterior norteamericana. De hecho, muchos presidentes han aludido a sus éxitos en política internacional como principal contribución al país durante sus mandatos, especialmente cuando su programa político en el frente interno se encontró con una dura oposición o incluso fracasó totalmente. En épocas recientes, Richard M. Nixon (1969-1974) y Jimmy Carter (1977-1981) son conocidos más por sus éxitos en política exterior (Nixon por su viaje a China y sus tratados de limitación de armamentos con la URSS, y Carter por los Acuerdos de Camp David entre Israel y Egipto), que por sus actividades en el interior. Este papel de jefe de la diplomacia confiere a la Presidencia un enorme poder y autoridad, que además no sufre apenas control por parte del congreso ni de ningún otro órgano político del país. Con el tiempo, los presidentes de EE.UU. han ensanchado este poder y esta autoridad inherentes al cargo, al ir ampliando poco a poco sus actividades como jefes de la diplomacia.

En ausencia de una Monarquía constitucional, en la que los deberes del ejecutivo se reparten entre un rey y un primer ministro, el Presidente de los EE.UU. debe cumplir también el papel de jefe del estado. Estos deberes ceremoniales del presidente son muchos, y también se han ampliado desde los días de George Washington. Por ejemplo, el Presidente tiene hoy a su cargo depositar periódicamente una corona ante la Tumba del Soldado Desconocido, en el Cementerio Nacional de Arlington. Frecuentemente debe acudir a inaugurar las ferias más importantes, como las exposiciones universales. Y cada vez la presidencia tiene más vínculos con el mundo deportivo. Ya se ha convertido en una rutina el que se invite a los ganadores de la Liga de Béisbol, de la Supercopa de Fútbol Americano, de la Copa Stanley de Hockey -si es un equipo norteamericano-, y del campeonato NBA de baloncesto, así como a los campeones olímpicos, a la Casa Blanca, en donde tiene lugar una ceremonia de felicitación formal por parte del Presidente. Son actos importantes, en la medida en que ayudan a establecer un vínculo entre el Presidente y su pueblo. Sirven para sugerir que el Presidente es una persona normal, igual al resto de los americanos, al identificarle con elementos de la cultura popular del país. También sirven para asociar la imagen del Presidente con ganar y con los campeones. En otras palabras: tales ceremonias públicas le aportan al Presidente un capital político importante, al 
identificar su figura con los gustos y con los intereses de la gente. En última instancia, el pueblo es la fuente principal de autoridad presidencial, sirviendo estos eventos ceremoniales para reforzar el vínculo que existe entre los norteamericanos y su presidente.

Otra de las funciones primordiales de la Presidencia es la de gestionar la economía. Es también una de las más difíciles a las que tiene que hacer frente, puesto que un político tiene poco control sobre los diversos factores que originan y sostienen una economía sólida. El Presidente asume las tareas de ayudar a resolver los conflictos laborales, aumentar el empleo, y garantizar la solidez y la seguridad del mercado de valores. También se espera de él que proteja a las industrias norteamericanas frente a la competencia extranjera, y que salvaguarde los puestos de trabajo de sus ciudadanos, evitando la deslocalización de empresas hacia áreas de salarios más bajos. Casi nada de todo esto está bajo el control de un Presidente, pese a lo cual una economía en mal estado es siempre una de las señales de alerta de un mandato presidencial con problemas. George H.W. Bush (1989-1993) aprendió que incluso un presidente capaz de llevar a la nación a la victoria en la guerra, podía verse expulsado del cargo en las elecciones debido a la mala situación económica en la paz, tal y como le sucedió a él en 1992. Herbert Hoover (1929-1933) también perdió la reelección casi exclusivamente por la percepción popular de que no estaba haciendo lo suficiente para combatir la recesión económica que produjo la Gran Depresión. La lección para todos los presidentes está clara; a falta de una economía sólida, el pueblo americano debe cuando menos percibir que su Presidente está comprometido activamente en tratar de corregir la situación.

Al Presidente se le supone la vocación de dirigente eficaz de su propio partido. La Presidencia es el mayor objetivo de ambos partidos políticos, Demócratas y Republicanos, en parte por la estatura que le confiere al partido que ocupa en el momento dicho cargo. El partido que tenga la Presidencia en sus manos, detenta la agenda social y legislativa de la nación durante cuatro o más años. Además, la capacidad de nombrar cargos que tiene el Presidente implica que en cada elección presidencial está en juego una enorme cantidad de influencia dentro de la Administración. El Presidente es también el portaestandarte del partido, y en este sentido se espera de él que haga campaña a favor de todos aquellos candidatos que optan a otros cargos políticos, desde senadores hasta simples alcaldes. Se le convoca para que haga apariciones personales durante campañas para elecciones cruciales, a fin de mantener la fortaleza y cohesión del partido a escala nacional y local. Igualmente importante, el Presidente debe intervenir como estrella principal en actos destinados a recaudar fondos, para asegurar una financiación del partido que sea suficiente para poder competir en las campañas electorales en todo el país. Estos actos sirven también para cimentar nuevas coaliciones políticas, y para atraer nuevos afiliados al partido. En otras palabras, se espera que las conexiones del Presidente sean lo suficientemente 
extensas como para conseguir que otros candidatos del partido ganen sus respectivas elecciones.

Finalmente, el Presidente debe ser un líder nacional, un caudillo para su pueblo. El pueblo americano quiere pensar que en tiempos de crisis, su Presidente está al mando, y que tiene presente en lo más profundo de sí el interés de la nación. En tiempos de guerra el Presidente debe mostrar firmeza, coraje, y confianza en sí mismo. En tiempos de crisis, el Presidente debe mostrar que tiene sentimiento y fortaleza de carácter suficientes como para conducir a la nación con éxito hacia aguas más tranquilas. El Presidente también debería ser capaz de dirigir a la nación hacia nuevos desafíos, e inspirar en los norteamericanos el servicio a la patria, del modo en que lo hizo John F. Kennedy (1961-1963) en su discurso inaugural cuando afirmó, «no preguntéis lo que vuestro país puede hacer por vosotros; preguntaos lo que vosotros podéis hacer por vuestro país" ${ }^{3}$. Mantener el liderazgo nacional, y que el pueblo americano lo perciba de esta manera, es probablemente la función más importante del presidente.

Todo lo anterior constituiría la lista de funciones del Presidente. Las expectativas del pueblo americano, de la élite política, de la Administración federal, y de la comunidad mundial demandan todo ésto de la persona que pretenda ser presidente de los EE.UU. Ya Lyndon B. Johnson (1963-1969) escribió que «La Presidencia ha convertido a todo hombre que la ocupó, por pequeño que fuese, en más grande; y por grande que fuese, en no lo bastante grande para ella» ${ }^{4}$. A lo largo del presente trabajo, examinaremos el origen y la evolución histórica del cargo de Presidente, veremos el lugar que ocupa la Presidencia dentro del sistema político de EE.UU., y compararemos el sistema presidencial norteamericano con el sistema parlamentario, a fin de tratar de explicar por qué el presidencialismo ha resultado eficaz en los EE.UU. mientras que parece no serlo en otros lugares del mundo.

\section{INTRODUCCIÓN HISTÓRICA: EL NACIMIENTO DE LA PRESIDENCIA}

La construcción del sistema presidencial norteamericano nació de las grandes deficiencias que se hicieron aparentes en los Artículos de la Confederación, y del contexto histórico de necesidad de, y a la vez sospecha

\footnotetext{
${ }^{3}$ Ridings and Mclver, Rating the Presidents, 226.

${ }^{4}$ Bunch, et al, The American Presidency, prefatory pages.

${ }^{5}$ La información en esta sección proviene de las siguientes fuentes: Bennett, The American Presidency 1945-2000, vii-xiv, 1-21, 246-262; Bunch, et al, The American Presidency, 27-38; Dwaynes and Sussman, The American Presidency and the Social Agenda, 1-31, 32-35, 58-62, 63-68, 82-88, 89-94, 111-113, 120145, 148-153; Genovese, The Power of the American Presidency, 1-57; Gregg. The Presidential Republic, 79-113; Michaelsen, Creating the American Presidency, 79-136; Riccards, The Ferocious Engine of Democracy, 7-30; Thach Jr., The Creation of the Presidency; Wood, The Creation of the American Republic, 543-564.
} 
hacia, un poder ejecutivo fuerte en los años de formación de la joven república. Los Artículos de la Confederación eran un documento diseñado en torno a la noción de «federalismo colectivo», en el que los estados retenían más autoridad que el gobierno central o federal. Tal y como descubrieron los padres constitucionales, la supervivencia de los EE.UU. como unidad requirió de un «federalismo directivo», que exige una autoridad ejecutiva fuerte. Los Artículos se mostraron casi totalmente ineficaces para administrar un país naciente en el contexto de guerra y de inestabilidad social de aquellos años.

El paso de los Artículos de la Confederación a la actual Constitución debe contemplarse dentro de su contexto histórico, compuesto por una serie de problemas específicos del siglo XVIII. En primer lugar, los Artículos carecían de mecanismo alguno para forzar a los Estados a que respetasen y acatasen la autoridad del Congreso. Los estados rechazaron pagar la deuda pública común, acuñaron su propio papel moneda, y levantaron barreras aduaneras entre ellos. En segundo lugar, los débilmente cohesionados Estados Unidos habían emitido una gran cantidad de deuda durante su Guerra de Revolución o de Independencia, y la inflación se había disparado. Tampoco los Artículos brindaban ninguna solución colectiva para este problema. Toda decisión tomada por el Congreso tenía que ser ratificada después por todos los estados; de forma que un estado cualquiera podía hacer naufragar la propuesta de legislación común mediante su solo disenso. Tercero, el malestar social era un problema que había provocado gran inquietud entre las clases terratenientes, en las cuales se encuadraban casi todos, si no todos, los Padres de la Constitución. En particular, el problema social de las revueltas de los deudores estaba sirviendo como aviso a las élites acomodadas del país de los peligros de una democracia desde abajo, o de cualquier cosa que no fuera una democracia representativa y deliberativa. En concreto la rebelión de Shay, una revuelta de deudores que tuvo lugar en Massachusetts, se vio como un indicio de que los estados no tenían poder para controlar a sus propias poblaciones, y que se necesitaba una solución común más efectiva para atajar tales rebeliones en el futuro.

Casi ya desde el final de la Guerra de Independencia, los Padres de la Constitución se habían dado cuenta de que hacía falta revisar los Artículos de la Confederación. ${ }^{6}$ La experiencia vivida entre 1783 y 1787 les terminó de convencer de que se necesitaba alguna otra forma de organización política y documento organizativo, si se quería que los EE.UU. sobreviviesen. Su incapacidad para revisar los Artículos les llevó a diseñar un sistema en-

${ }^{6}$ A lo largo del presente trabajo me referiré alternativamente a los Padres de la Constitución, o constituyentes, y a los Padres Fundadores, para indicar respectivamente a los Creadores de la Constitución y a los Fundadores de la República norteamericana: se trata de dos fórmulas comunes que denotan a dos grupos muy similares pero no exactamente iguales de aquellos hombres que estuvieron implicados en la creación de los Estados Unidos de América. 
teramente nuevo, algo revolucionario para su época - un sistema federal, el cual reemplazaría muchos de los derechos de los estados en aras de la creación de un gobierno nacional con poder real. Doce de los trece estados enviaron delegados a la Convención de Filadelfia convocada para revisar los Artículos de la Confederación en 1787 (Rhode Island se negó a hacerlo). Los delegados descubrieron muy pronto que varias delegaciones eran proclives a derogar totalmente los Artículos y redactar un documento del todo nuevo, aunque era un acto ilegal. Casi desde el principio, la Convención reunida para modificar los Artículos se convirtió en una Convención constituyente.

Los Fundadores no tenían una visión clara acerca de cómo sería un sistema federal. Los detalles hubieron de trabajarse en sesiones de comités cuyos debates se extendieron durante el invierno, la primavera y el verano de 1787. Lo que sí sabían es que el Estado necesitaba de algún tipo de poder ejecutivo fuerte. Los presidentes del Congreso previstos en los Artículos, con sus mandatos de sólo un año cada uno, claramente no tenían ninguna autoridad ejecutiva real. Lo cual nos lleva a considerar otro elemento presente en la creación del Estado y del poder ejecutivo de los EE.UU., cual es el profundo recelo que el ejecutivo despertaba en los americanos en general y en los Fundadores en particular. La ambivalencia de éstos con respecto al poder ejecutivo procedía directamente de un continuado debate político suscitado entonces entre poder ejecutivo frente a poder legislativo.

Las ideas de los Fundadores acerca de las relaciones políticas eran herederas directas de las teorías de Inglaterra sobre el conflicto de poderes entre la Corona y el Parlamento, entre la autoridad política y el órgano representativo. En concreto, John Adams, Thomas Jefferson, y James Madison eran buenos conocedores de la teoría política inglesa referente a esta dialéctica entre la autoridad gobernante y la soberanía de la nación, según se reflejaba en los escritos de John Locke en el siglo XVII y de William Blackstone en el siglo XVIII ${ }^{7}$. La Guerra de Independencia de EE.UU. había estallado en un momento en que este debate se encontraba en un punto crucial de transición, en un momento en que las interpretaciones más difundidas de Locke y de Blackstone habían empezado a decantarse a favor del poder legislativo y en contra del ejecutivo.

Los órganos representativos de la América colonial, sus concejos municipales y sus asambleas estatales, establecidos originariamente por los ingleses, comenzaron a irritarse bajo la autoridad del poder ejecutivo que constituía el representante de la monarquía, el Gobernador Real. En esta pugna, poco a poco, los órganos locales comenzaron a verse a sí mismos

\footnotetext{
${ }^{7}$ Riccards, The Ferocious Engine of Democracy, 8-11. Los Fundadores estaban familiarizados con las obras de Locke: Two Treatises on Government (1688) y de Blackstone: Commentaries on the Laws of England (1765-1769).
} 
como la autoridad política más importante, y como los verdaderos representantes de la voluntad popular. Una vez se hizo pública la Declaración de Independencia y comenzó la Guerra, los dirigentes revolucionarios locales exhortaron a sus estados a que redactasen sus propias constituciones, las cuales glorificaron la visión en boga de colocar el legislativo por encima del ejecutivo.

Aunque la mayoría de cartas magnas estatales reflejaron esta ambivalencia frente al poder ejecutivo, dos estados se opusieron en sus constituciones a la marea dominante: Massachusetts y Nueva York. Sus dos constituciones establecieron ejecutivos fuertes y eficaces, encarnados por sus gobernadores estatales. Ambos estados demostraron a la postre estar mejor gobernados que algunos de los otros, caracterizados por legislativos fuertes y ejecutivos débiles. Otro ejemplo histórico positivo del que los constituyentes pudieron extraer consecuencias fue el comportamiento durante la guerra de los gobernadores, así como el papel de George Washington en coordinar sus esfuerzos. Las comunicaciones entre ellos, frecuentes y eficaces, contribuyeron al éxito de la campaña militar, y proporcionaron un buen ejemplo de las ventajas que tenía contar con un ejecutivo fuerte.

¿Qué formas de poder político tuvieron en mente los fundadores? ¿Qué sistemas políticos pudieron tomar en consideración antes de su llegada a Filadelfia? Históricamente, existían varios modelos en los cuales pudieron inspirarse, además de las experiencias familiares e inmediatas recién comentadas. Fundadores y Padres de la Constitución eran gente de cultura muy extensa, y sin duda conocedores de precedentes históricos tales como la democracia ateniense, cuyo colapso acrecentaba sus temores acerca de la inestabilidad del sistema democrático puro. Conocían también la República romana, y su historia admonitoria acerca de los riesgos de rivalidad entre ejecutivo y legislativo, que acabaron por traerle su ruina y hacerle caer en un imperio. Además, los constituyentes vieron otra nota positiva de autoridad política en la organización de la Confederación Iroquesa. De hecho, su organización política serviría de modelo para el Plan de Albany de Benjamin Franklin de 1754, estando los constituyentes familiarizados con las virtudes y los vicios de tal sistema. ${ }^{8}$

Todo este cúmulo de circunstancias sociales, políticas y económicas, tanto históricas como contemporáneas, se hicieron sentir enormemente entre los delegados mientras discutían en Filadelfia acerca de la naturaleza que tendría el nuevo poder ejecutivo. Allí se debatió cada elemento: los poderes que tendría el nuevo cargo, su periodo de mandato, su título, su renovación y su retirada, y hasta la manera de dirigirse al mismo. Fue James Wilson, delegado de Pennsylvania, quien propuso la idea de un único cargo popularmente electo. Pero, temerosos de una excesiva dependencia de la

${ }^{8}$ Genovese, The Power of the American Presidency, 3-6. 
voluntad popular por parte del futuro presidente, y también quizá de los riesgos de demagogia, los constituyentes modificaron la propuesta de Wilson, con activa participación de éste, desarrollando una institución intermedia denominada Colegio Electoral. También se ha dicho que los constituyentes se decantaron por una figura presidencial poco elaborada, con muchas áreas vagas y ambiguas, preguntándose por qué: la respuesta fue George Washington. ${ }^{9}$

Quizá no deba sorprender que el hombre al que veían más adecuado para ocupar este nuevo cargo fuera el propio presidente electo de la Convención constitucional. En verdad, según todas las fuentes, Washington parece como la única figura que inspiraba a todos respeto y confianza suficientes como para inaugurar debidamente el nuevo cargo político. He aquí una de esas fuentes, el relato de Pierce Butler, delegado de la Convención:

Estoy presto a reconocer que sus poderes (los del Presidente) son grandes, mayores de lo que yo en principio estuve dispuesto a permitir. No creo, entre nous, que hubieran sido tan grandes de no haber puesto muchos de los delegados sus ojos en la persona de George Washington como Presidente; y de no haber influido en sus ideas acerca de los poderes que debían dársele al Presidente sus opiniones acerca de las virtudes de aquél. ${ }^{10}$

Realmente Washington pareció la persona idónea para el puesto. Su carácter humilde y a la vez seguro de sí mismo sin duda mitigaría los temores de muchos Padres Fundadores acerca del grado de poder que estaban concediendo al ejecutivo. La cita siguiente sirve para demostrar ese carácter:

Los participantes en el nuevo Estado sabían que estaban estableciendo modelos para el futuro. Y nadie parecía más consciente de esta responsabilidad que el primer presidente.

Siempre pendiente del simbolismo, George Washington se esforzó por lograr un balance exquisito entre actuar de forma demasiado regia y actuar de forma demasiado igualitaria. Optó por la fórmula «Señor Presidente» para dirigirse a su persona; pero preferia hacer una reverencia a sus invitados en vez de darles la mano.

Lo que es más importante, Washington estableció la Presidencia como poder central de la rama ejecutiva del nuevo Estado. Mantuvo cuidadosamente el mando sobre el cargo, no cediendo jamás su autoridad a los secretarios del gabinete, ni delegando sus competencias en ninguna de las otras ramas del Estado. ${ }^{11}$

Los constituyentes confiaron en que Washington rellenaría los detalles de su puesto durante el cumplimiento de sus deberes, sobre todo teniendo en

\footnotetext{
${ }^{9}$ Ibid., 8.

${ }^{10} \mathrm{lbid}$., 8 and Bunch, et al, The American Presidency, 33.

${ }^{11}$ Bunch, et al, The American Presidency, 34.
} 
cuenta que habían dejado la descripción del cargo incompleta. La Presidencia de los EE.UU., pues, proviene tanto de las circunstancias inmediatas que rodearon a la Convención, como del contexto histórico y del debate político continuado descritos anteriormente. El papel de Washington durante la Convención, y la confianza que los constituyentes tuvieron en su capacidad para manejar el cargo, dieron como resultado una Presidencia cuyas competencias y deberes podían, en gran parte, definirse de manera individualizada. Nadie era más consciente de ello que el propio Washington, quien afirmó que "En nuestro progreso hacia la felicidad política mi estación es nueva; y si puedo utilizar la expresión, camino sobre un terreno jamás antes pisado.. ${ }^{12}$

Sin saberlo, esa confianza que los constituyentes depositaron en el primer presidente trajo como consecuencia la posibilidad de expandir el poder ejecutivo, hasta cotas nunca concebidas por ellos, por parte de los sucesivos ocupantes del cargo, quienes obviamente podrían no obrar con la grandeza de miras y los escrúpulos mostrados por George Washington. No obstante, incluso un rápido vistazo al Artículo Dos de la Constitución, que describe los deberes, facultades, competencias y limitaciones del cargo, basta para reconocer la cautela con que los Padres de la Constitución aceptaron finalmente la existencia de un poder ejecutivo único, con un mandato de cuatro años renovable. Los poderes y las limitaciones de la Presidencia, tanto constitucionales como basados en otros fundamentos, se discutirán más adelante pero por el momento se puede decir en justicia, que los constituyentes hicieron todo lo que estaba en su mano por asegurarse de que existían suficientes controles institucionales sobre el Presidente como para evitar que éste se convirtiera en una suerte de monarquía hereditaria o de dictadura personal.

La Convención constitucional no fue el único obstáculo franqueado por los nuevos Estados Unidos de América. De hecho, ahora los estados tenían que ratificar el nuevo documento y ello, dada su desconfianza general hacia el poder ejecutivo, no iba a estar exento de dificultades. Durante todo el resto de 1787 y 1788 tuvo lugar un debate extraordinariamente público entre proponentes y oponentes del nuevo Estado diseñado por la Constitución, en especial el nuevo cargo del Presidente. La serie de ensayos políticos «El Federalista» (Federalist Papers) revela los argumentos que utilizaron los defensores del nuevo Estado, así como algunas de las reservas suscitadas. Desde el principio existió también una oposición muy activa y ruidosa a la nueva Constitución por parte de los así llamados "Anti-Federalistas", los cuales centraron gran parte de sus preocupaciones en la naturaleza del órgano ejecutivo previsto en la Constitución. Algunos, como el delegado de Filadelfia Elbridge Gerry, pensaban que las ramas ejecutiva y legislativa del Estado aparecían «demasiado mezcladas» en el documento. Otros hicieron

12. Ibid. 
un nuevo llamamiento a favor de un órgano ejecutivo plural, propuesta que ya había surgido durante la Convención. Otros más, como el Gobernador de Nueva York George Clinton, expresaron sus temores hacia un mandato de duración mayor que un año. Y, como caso destacado, Thomas Jefferson, entonces embajador en Francia y más tarde presidente, mantenía reservas acerca de la posibilidad de reelección prevista en la Constitución. ${ }^{13}$

Los Federalistas se enfrentaron a estos argumentos tratando de resaltar el carácter derivado del cargo. James Madison ensalzó los límites que la propia Constitución le imponía al cargo. Alexander Hamilton hizo notar que los poderes del Presidente eran «en algunos aspectos mayores, en otros aspectos menores que los del gobernador de Nueva York." Recordó así mismo a los oponentes que el poder de veto presidencial estaba calcado de la Constitución de Massachusetts. Hamilton refutó directamente las críticas anti-Federalistas que comparaban a la Presidencia con una Monarquía en el artículo «Federalist» número 69:

El Presidente de los Estados Unidos sería un funcionario elegido por el pueblo para un periodo de cuatro años; el Rey de Inglaterra es un Príncipe perpetuo $y$ hereditario. El uno sería susceptible de castigo personal y de caer en desgracia [mediante el «impeachment»]; la persona del otro es...inviolable. ${ }^{14}$

Hamilton continúa comparando estos dos tipos de órgano ejecutivo en un largo párrafo, y lo termina con una puya retórica hacia aquéllos incapaces de ver la diferencia entre ambos:

¡El uno no tiene la menor parcela de jurisdicción espiritual, en tanto que el otro constituye la cabeza visible y gobierno de la iglesia nacional! ¿Qué podemos responderles a aquéllos que insisten en que dos cosas tan distintas se parecen la una a la otra? Lo mismo que debiera decirse a aquéllos que afirman que un Estado cuyo único poder estaría en manos de sirvientes del pueblo electos por periodos limitados, constituye una aristocracia, una monarquía y un despotismo. ${ }^{15}$

Junto a esta defensa de la Fresidencia hecha por Hamilton, también John Jay hizo notar que el nuevo sistema exigía contar con la opinión y el consentimiento del Senado para muchas de las acciones presidenciales. Con tales argumentos, al final los Federalistas se impusieron, y la Constitución consiguió ser aprobada, con el cargo de Presidente intacto. Fueron además lo bastante cuidadosos con el nuevo esquema político como para decidir que la primera tarea que acometería el nuevo Congreso al reunirse

\footnotetext{
${ }^{13}$ Riccards, The Ferocious Engine of Democracy, 24-26.

${ }^{14}$ Genovese, The Power of the American Presidency, 13.

${ }^{15}$ Ibid., 13.
} 
sería aprobar una declaración de derechos ${ }^{16}$. Pero la estructura del cargo de Presidente es tal, que la dialéctica que opone a ejecutivo frente a legislativo ha continuado hasta el presente. Al parecer, todavía hoy no se han olvidado algunas de las preocupaciones expresadas por los anti-Federalistas.

Hasta ahora he descrito brevemente el desarrollo histórico de la Presidencia tal y como ésta emergió del contexto teórico, político, social y económico vigente en el siglo XVIII. También se ha adelantado la naturaleza ambigua del cargo, obra de los propios Padres Fundadores, debido a la fe y confianza que éstos tenían en la capacidad de aquél que sabían iba a ser el primer presidente, George Washington. Diseñaron la Presidencia de forma incompleta, a sabiendas de que George Washington terminaría de definir el cargo, dejando con ello la tarea de la Presidencia sujeta a las personalidades y los deseos de los que en el futuro serían elegidos para ocuparla. Por tanto, la evolución posterior de la Presidencia informará el resto del presente trabajo, y se analizará en referencia a los 42 hombres que han seguido a George Washington en este cargo.

\section{LA PRESIDENCIA DE LOS EE.UU.: UN SISTEMA QUE FUNCIONA ${ }^{17}$}

Como hemos visto, la Presidencia norteamericana tiene un fundamento que nos retrotrae a los inicios de la república de los EE.UU. y a los dos documentos que proporcionaron las bases para su gobierno: los Artículos de la Confederación, y la Constitución de los Estados Unidos de América. Antes de examinar la Constitución más a fondo, habría que hacer algunas observaciones adicionales acerca de los Artículos de la Confederación, que estuvieron en vigor desde el 1 de marzo de 1781 hasta el 21 de junio de 1788, día en que New Hampshire se convirtió en el noveno estado, alcanzándose así la mayoría de dos tercios exigida por ley, en ratificar la actual Constitución de los Estados Unidos (previamente ratificada por la Convención el 17 de septiembre de 1787).

En líneas generales, los Artículos de la Confederación resultaron ser insuficientes como instrumento rector, ya que carecían de toda disposición acerca de una autoridad ejecutiva. Existía en ellos un Presidente del Congreso, pero no un órgano ejecutivo en el sentido de órgano supervisor federal. De hecho, en el documento no aparece mención alguna al ejecutivo hasta el artículo IX, y aun allí se hace referencia a los ejecutivos estatales, puesto que no existía, en ese estadio de desarrollo de los EE.UU., ningún

\footnotetext{
${ }^{16}$ Riccards, The Ferocious Engine of Democracy, 27-29.

${ }^{17} \mathrm{La}$ información en esta sección proviene de las siguientes fuentes: Bunch, et al, The American Presidency, 1-26; Riccards, The Ferocious Engine of Democracy, xi-xxii; Wood, The Creation of the American Republic 1776-1787, 565-618; Collier and Collier, Decision in Philadelphia, 1-3, 14-24, 30-42, 87$89,135-137,181-183,263-272,273-280,281-292$.
} 
órgano ejecutivo federal. La expresión que aparece de modo recurrente a lo largo de todo el documento: "los estados unidos reunidos en asamblea" ( "the united states in congress assembled"), es perfecta muestra de la independencia mantenida por los estados y de la falta de compromiso hacia una unión más estrecha ${ }^{18}$. Los Artículos fueron un documento oportuno en su momento, pero destinado a mostrar sus carencias al surgir una situación que requiriese (a) un esfuerzo colectivo y concertado. Los sucesos ocurridos tras la Declaración de Independencia y la posterior Guerra revolucionaria rápidamente alertaron a los Padres Fundadores de que los Artículos de la Confederación no tenían las previsiones que hacían falta para sustentar otra cosa que no fuese un sistema federal demasiado orientado hacia los derechos de los estados. Además, contenían numerosas estipulaciones engorrosas, destacando entre ellas la de que sólo podían modificarse con el consentimiento de todos y cada uno de los estados. Claramente, si las figuras máximas de la naciente Unión política deseaban crear un Estado más fuerte y estable, tendrían que buscar un gobierno federal con autoridad real. Igualmente, los estados debían retener suficiente soberanía como para poder actuar en su propio interés local en aquellos asuntos que fueran propios de cada estado.

La actual Constitución de los Estados Unidos se elaboró para cumplir estos propósitos. Consiguió un equilibrio aceptable entre los derechos de los estados dentro de la federación, y un poder federal suficiente para aquellos asuntos tanto internos como internacionales en los que se necesitaba unidad de dirección. La Constitución en sus tres primeros artículos detalla el catálogo de derechos y deberes de las tres ramas que componen el Estado norteamericano: el legislativo, el ejecutivo, y el judicial, y establece el sistema de equilibrio entre poderes que constituye la piedra angular del documento ${ }^{19}$. La Constitución es un documento extraordinario que combina el pragmatismo y sentido del gobierno norteamericano de la época con elementos de la teoría política europea, sobre todo de John Locke y de Charles Secondat, Barón de Montesquieu ${ }^{20}$. El sistema presidencial en EE.UU. se basa, por supuesto, en la relación entre las tres ramas del Estado tal y como éstas aparecen expresadas en la Constitución, razón por la cual debemos examinar este documento más atentamente.

El Artículo Uno de la Constitución trata de las responsabilidades del órgano legislativo bicameral del Estado: el Congreso, compuesto por el Senado y por la Cámara de Representantes. La Sección segunda, que regula la Cámara de Representantes, afecta a nuestro estudio especialmente, ya que confiere a este órgano en exclusiva la iniciativa del «Impeachment», o

\footnotetext{
${ }^{18}$ Collier and Collier, Decision in Philadelphia, 273-280.

${ }^{19}$ Ibid., 281-292 para consultar el texto de la Constitución de donde se han tomado todas las citas que aparecen en esta sección.

20 Véanse Locke: Two Treatises on Civil Government (1688) y Montesquieu: Esprit des Lois (1748).
} 
capacidad de procesar a un presidente y de destituirlo del cargo. La Sección tercera detalla el poder y la autoridad del Senado. De nuevo, nos encontramos aquí con un contrapoder frente a la rama ejecutiva, al afirmarse que «El Senado tendrá competencia exclusiva para enjuiciar todos los casos de Impeachments». Esta Sección continúa delimitando con más detalle el papel del Senado en este caso tan grave recogido en la Constitución, afirmando que «la Sentencia en casos de Impeachment no irá más allá de la retirada del cargo y la inhabilitación para ocupar y disfrutar de cualquier cargo de honor, confianza o provecho en los Estados Unidos: no obstante, la parte condenada se verá sujeta a Acusación, Enjuiciamiento, Sentencia y Pena conforme a la Ley». Sólo tres presidentes se han enfrentado con un proceso de impeachment: Andrew Johnson, Richard Nixon, y William Clinton. Johnson y Clinton llegaron a ser procesados, pero no se alcanzó la mayoría de dos tercios suficiente como para retirarles del cargo. Nixon por su parte dimitió antes de llegar a este extremo, pues tanto él como sus asesores sabían que no sobreviviría a la votación. Como vemos, el poder legislativo juega un papel extraordinariamente importante de control y balance de la autoridad del ejecutivo, gracias a esta capacidad de destitución que supone el procedimiento de impeachment. Aquí encontramos, una vez más, la preocupación de los constituyentes por limitar el poder ejecutivo, y su insistencia por someterlo a controles o contrapoderes.

El Artículo Dos de la Constitución trata de la rama ejecutiva del Estado: «El Poder Ejecutivo estará investido en un Presidente de los Estados Unidos de América». Su Sección segunda especifica la duración de su mandato, y el método de elección del Presidente - a través de un Colegio Electoral, en vez de una elección directa por votación popular. Aquí nos encontramos con los recelos de los Fundadores hacia un ejecutivo demasiado dependiente del deseo popular, así como con sus temores hacia una democracia popular con su potencial riesgo de demagogia por parte del ejecutivo. El Artículo Dos también dispone que «Nadie salvo un ciudadano nacido en los Estados Unidos, o que sea ciudadano de los Estados Unidos en el momento de adopción de la presente Constitución, podrá ser elegido para el cargo de Presidente; tampoco podrá ser elegido para dicho cargo quien no haya alcanzado la edad de treinta y cinco años, y no haya sido catorce años residente en los Estados Unidos». Indica después lo que debe hacerse en el caso de que el Presidente ya no sea capaz de cumplir los deberes inherentes a su cargo, así como que se trata de un cargo remunerado a intervalos específicos. Obliga al Presidente a prestar el Juramento Presidencial antes de asumir los deberes y facultades inherentes al cargo. La Sección segunda recita los poderes del Presidente: «EI Presidente será comandante en jefe del Ejército y de la Marina de los Estados Unidos, y de la Milicia de los diversos Estados, cuando se convoque a ésta en Servicio de los Estados Unidos". Concede al Presidente el derecho de gracia respecto de delitos cometidos contra los Estados Unidos, «excepto en los casos de Impeachment». Describe la capacidad del Presidente para concertar tratados, que 
deberán contar con la opinión y con el consentimiento del Senado (otro control al poder ejecutivo), y su poder de designación de cargos administrativos, judiciales, y otros dentro del Estado, algunos de ellos sujetos a la aprobación y veto del Congreso y otros no, a discreción del propio legislativo. La Sección tercera establece que el ejecutivo debe presentar al legislativo un informe sobre el estado de la Unión, al tiempo que debe «encomendar a su consideración cuantas medidas estime necesarias y oportunas». Afirma la facultad del Presidente, «en ocasiones extraordinarias», de convocar o de clausurar ambas cámaras del Congreso. Enuncia también la responsabilidad del Presidente de recibir a los embajadores y otros ministros, dirigir a todos los funcionarios de los Estados Unidos, y «cuidar de que se ejecuten fielmente las leyes». Finalmente, la Sección cuarta advierte de que «El Presidente, el Vicepresidente y todos los otros funcionarios de los Estados Unidos, podrán ser retirados de sus cargos en caso de Impeachment, y de Condena, por traición, Cohecho, u otros delitos graves», expresando así aunque sea de manera muy general, tanto un código de conducta para el cargo, como la idea de que el Presidente es un funcionario más, que debe obrar dentro de la legalidad y no por encima de ella.

El Artículo Tres de la Constitución trata de los deberes y las responsabilidades del poder judicial del Estado. Aunque no aborda expresamente la capacidad de esta rama de controlar al Presidente, la Sección segunda asigna al poder judicial «todas las causas, de Derecho y de Equidad, que deriven de la presente Coristitución, de las Leyes de los Estados Unidos, y de los Tratados celebrados, o que se celebren en el futuro, bajo su Autoridad". Esta capacidad del alto tribunal de determinar lo que es o no constitucional le permite, en teoría, controlar tanto al poder legislativo como al ejecutivo. A través de la historia presidencial, el Tribunal Supremo ha dictado varias decisiones que supusieron un impacto en el cargo; las más recientes fueron durante la administración de Nixon, acerca del privilegio del ejecutivo con respecto a las grabaciones de las conversaciones en posesión del Presidente, y en la causa de Bush contra Gore en la que el Tribunal Supremo entregó las elecciones presidenciales de 2000 a George W. Bush pese a existir evidencias de fraude electoral en Florida, el estado clave que decidió la composición del colegio electoral, y por tanto la elección, -estado en el que el Gobernador, Jeb Bush, era el hermano del candidato-.

El sistema presidencial de EEUU, por tanto, se funda en una interrelación entre las tres ramas del Estado, pero sobre todo entre las ramas ejecutiva y legislativa - Presidente y Congreso. La Constitución, como hemos visto, se muestra especialmente vaga y ambigua acerca de los deberes efectivos del Presidente. De hecho no dice nada acerca de las tareas cotidianas del cargo. También hemos visto que los constituyentes dejaron así el cargo de forma deliberada porque sabían que George Washington iba a ser el primer presidente y, pensaban, definiría su puesto proporcionando un modelo para la presidencia que podrían seguir sus sucesores en el cargo. Por tanto, el 
sistema presidencial norteamericano sería en realidad la confluencia de: la iniciativa personal del Presidente, la relación entre el Presidente y el Congreso, la popularidad que tenga el Presidente con su pueblo, las directrices constitucionales, el deseo que tenga el propio Presidente de explorar estas áreas de indefinición y ambigüedad, y el cúmulo de circunstancias impredecibles que rodean a cada momento histórico en particular. Al menos, esto es lo que era antes del advenimiento de los modernos medios de comunicación de masas, en especial la radio y la televisión.

Las funciones de la Presidencia de EE.UU., se asemejan en cierto sentido a una colmena, al tratarse de un sistema político jerárquico y altamente organizado de muchas personas trabajando para un jefe. Buena parte del tremendo poder de un Presidente norteamericano se deriva de la naturaleza colectiva del sistema presidencial. Existe una buena dosis de "autoridad» en manos de cada presidente de EE.UU., a causa de una combinación entre la naturaleza colectiva del cargo, y el enfoque personal que pueda darle al mismo cada nuevo presidente electo. El poder que el sistema le confiere a la persona que ocupa esta posición es obvio y no superado por ningún otro sistema político, como lo demuestra la siguiente afirmación:

Hoy día, ningún monarca extranjero sobrepasa en autoridad escrita o asumida al presidente de los Estados Unidos, incluso contando con todo el esfuerzo que supone ganar la nominación por su partido, demócrata o republicano, y después ganar las elecciones. 21

La naturaleza colectiva del sistema deriva de la variedad que encontramos de funciones y de enfoques individuales al asumir el cargo. La Presidencia es varios cargos diferentes en uno solo $^{22}$. Se trata ante todo de un cargo administrativo. Este es el elemento ejecutivo: las funciones del Presidente como administrador o gestor supremo del país, mediante la aplicación de las leyes promulgadas por el Congreso. Ningún proyecto se convierte en ley hasta que el Presidente, como representante de la rama ejecutiva del Estado, estampa su firma en el mismo.

Sin embargo, la presidencia es más que una función administrativa. Incluye también un componente de vasallaje, en el que el Presidente actúa como verdadero caudillo político, al dispensar una protección que va asociada a su victoria en las elecciones. Existen innumerables cargos dentro del gobierno federal de los EE.UU. cuyo nombramiento corresponde al Presidente. Es costumbre que estas posiciones vacantes vayan a aquellas personas que trabajaron con, o en general a favor de la elección de, el ocupante del cargo. Por ejemplo, aquéllos que aportaron sumas de dinero para la

\footnotetext{
${ }^{21}$ Riccards, Ferocious Engine of Democracy, xii.

22 ĺbid., xi-xiii. Las categorías "administrativa», "ceremonial», "púlpito privilegiado (bully pulpit)», e «imperial» aquí presentadas proceden de la obra de Riccards.
} 
campaña presidencial a menudo reciben embajadas en recompensa, en tanto que los amigos personales del Presidente pueden recibir cargos entre el personal de la Casa Blanca o en otros lugares de la vasta burocracia existente en Washington, D.C. Hay que recordar a este respecto que muchos cargos nombrados por el Presidente están sujetos a la aprobación por el Congreso, pero que ello constituye a menudo una simple formalidad, salvo que Presidente y Congreso estén enfrentados o pertenezcan a partidos políticos distintos, y el nombramiento en cuestión haya pasado a convertirse en asunto partidista. Este suele ser el caso cuando se trata de la designación presidencial de los poderosos e influyentes magistrados del Tribunal Supremo, así como de otros jueces federales.

La Presidencia es también un «púlpito privilegiado». Igual que haría un predicador, el Presidente puede utilizar el prestigio y la autoridad del cargo para luchar por conseguir el apoyo público a ciertos asuntos sociales o políticos, proyectos legislativos, o programas nacionales. Los Presidentes hacen apariciones personales o televisadas, emplean espacios en periódicos y revistas, y ocupan tiempo de la radio, para generar apoyo público a favor de, por ejemplo, ir a la guerra, presionar al Congreso para que promulgue una ley, orientar la política de educación nacional, aupar a un cargo a un candidato de su partido, y toda una amplia gama de otras actividades que sería muy largo enumerar.

Finalmente, la expansión durante el siglo $X X$ de las competencias inherentes e implícitas del Presidente, ha dado lugar a un elemento «Imperial» en el sistema presidencial americano. Esta expansión ha acaecido a iniciativa del propio Presidente y mediante ese poder presidencial de conformar la agenda social, política y económica del país gracias al veto de que dispone. El Presidente tiene a su disposición personal un extenso cuadro de servicios y de consejeros que ha contribuido a aportarle al cargo una mayor autoridad. Miles de personas sirven al Presidente en la actualidad en lo que se ha dado en llamar "oficinas para-constitucionales", como el Consejo de Seguridad Nacional y el Consejo de Expertos Económicos. Estos órganos no se describen en la Constitución, pese a lo cual contribuyen a las funciones expandidas de la Presidencia, y le confieren una gran cantidad de autoridad extra-constitucional al cargo.

El sistema presidencialista de EE.UU. exige muchas cosas de la persona que ocupe esta posición, y entre ellas no es la menor la capacidad de ejercer de forma responsable tan enorme poder en tan amplia variedad de aspectos, y a la vez permanecer fiel a los ideales expresados en el juramento presidencial - una declaración que todos deben pronunciar al asumir el cargo:

Juro (o afirmo) solemnemente que serviré fielmente en el Cargo de Presidente de los Estados Unidos, y que haré todo lo posible para preservar, proteger y defender la Constitución de los Estados Unidos. ${ }^{23}$

${ }^{23}$ Bunch, et al, The American Presidency, 60. 
Esta breve declaración define la tarea del Presidente como un servicio. El Presidente deberá, por encima de todo en la ejecución de los deberes de su cargo, "preservar, proteger, y defender» la Constitución. Será el cumplimiento de ese deber, o realmente la naturaleza de esa obligación, lo que o bien definirá la grandeza de un Presidente o sellará su fracaso como tal. En otras palabras, en el núcleo del sistema político de los EE.UU. está la Constitución, que teóricamente proporciona el patrón objetivo con el cual todos los presidentes norteamericanos pueden conocer los deberes de su cargo, y por ende juzgar su propio grado de cumplimiento en contraste con el de sus predecesores.

Más aún, el diseño del sistema convierte al Presidente en objeto de una enorme expectación popular. En este sentido, Michael Riccards hizo notar que el cargo «ha sido un prisma a través del cual se han refractado las preocupaciones y las ambiciones de los americanos ${ }^{24}$. Riccards lo deja claro cuando afirma:

También se está haciendo evidente que ...la importancia central, aunque no única del Presidente radica en sus funciones públicas y de portavoz de la comunidad, y en la habilidad de cada ocupante del cargo de expresar las ideas e ideologías, las esperanzas y los temores de la gente de su propia generación.

$Y$ la habilidad de cada Presidente en identificarse con motivos tan poderosos como el federalismo, la Unión Perpetua, el internacionalismo, el Destino Manifiesto, y la igualdad, ha dictado en gran medida el éxito que cada uno consiguió en pasar de ser dirigentes de su generación a ser figuras históricas. ${ }^{25}$

Cada nuevo Presidente que asume el cargo, y ha habido cuarenta y tres hasta la fecha, se vuelve consciente de la naturaleza histórica de su posición, de la autoridad que se le confiere al ocupante de la misma, y de la gran expectación y escrutinio público que acompañarán a su tarea.

La Presidencia, y el sistema que gobierna su actuación, ha sufrido una evolución histórica, que nos ha proporcionado varios modelos o maneras en que se ha abordado el desempeño de esta posición. Riccards ha identificado y nombrado seis modelos de presidencia de los EE.UU., que considero pueden ser útiles para entender los estilos y los enfoques diferentes que han empleado los presidentes a la hora de cumplir con las expectativas institucionales y públicas volcadas en ellos. Se trataría de los modelos Federalista, Jeffersoniano, Jacksoniano, Whig, de Lincoln, y de Roosevelt de cumplimiento presidencial. ${ }^{26}$

\footnotetext{
${ }^{24}$ Ricards, Ferocious Engine, xvi

${ }^{25}$ Ibid., xvii-xviii.

${ }^{26}$ Ibid., xvil-xxi. En palabras del propio autor, consisten en líneas generales y no en categorías rígidas. Muchos presidentes enfocaron su tarea en formas que mezclaban estos enfoques.
} 
El modelo Federalista, como el nombre sugiere, procede de los inicios de la república, y fue el establecido por el primer Presidente de EE.UU., George Washington (1789-1797), y continuado por John Adams (1797-1801), y en cierta medida por John Quincy Adams (1825-1829). Cayó luego en el olvido durante largo tiempo hasta que fue retomado, desempolvado y revisado por Eisenhower (1953-1961), Reagan (1981-1989), y George H.W. Bush (1989-1993). Básicamente, el modelo depende de la popularidad del Presidente entre un abanico muy amplio del pueblo americano, a menudo por encima de las posturas políticas. El Presidente juega un papel fuerte en la política exterior, y se desinteresa por la política estrictamente de partidos. En el modelo Federalista de la Presidencia, las ocasiones de protocolo y pompa oficial son momentos propicios para defender y afianzar la posición del ocupante del cargo. Los presidentes federalistas se muestran conservadores en asuntos sociales y económicos, e indiferentes frente a las controversias legales, excepto cuando puedan interferir en los derechos del ejecutivo. En el modelo Federalista, puede verse al Presidente centrado sobre todo en las facetas administrativas y ceremoniales de su cargo.

Cuando Thomas Jefferson (1801-1809) ganó la Presidencia, inauguró un nuevo enfoque del cargo, que lleva su nombre. Jefferson y sus sucesores inmediatos hicieron revivir con fuerza la política de partidos políticos, y crearon un modelo de partido gobernante fuerte. De hecho, el enfoque Jeffersoniano puso el énfasis en una cooperación cercana entre las ramas legislativa y ejecutiva, una desviación del modelo Federalista favorecido por Washington. Este modelo se fundaba en «un liderazgo coherente, mores democráticas, y un ejecutivo casi oculto " ${ }^{27}$. El modelo de Jefferson resultó muy poderoso más tarde, al ser un primer paso hacia la categoría de «presidencia imperial», en la que el Presidente proporciona un caudillaje de alcance nacional.

La Presidencia de Andrew Jackson (1829-1837) dio origen a otro cambio en la manera de enfocar la tarea presidencial. Los Jacksonianos han revivido la faceta populista de la presidencia, al concebirlo como un cargo que mantiene una comunicación estrecha con el pueblo americano. Pero los Jacksonianos estuvieron más interesados en afirmar el poder del ejecutivo frente al del legislativo a la hora de sacar adelante iniciativas legislativas específicas. Los Jacksonianos emprendieron también una política exterior expansionista, capaz incluso de emplear la fuerza armada para sus objetivos en mi opinión sentaron así dos modelos desafortunados y peligrosos de cara a los futuros presidentes.

La reacción frente al modelo anterior vino de la mano de los presidentes William Henry Harrison (1841) y John Tyler (1841-1845), estando en uso el nuevo modelo, bautizado por Riccards como Whig, ocasionalmente hasta la

${ }^{27}$ Ibid., xviii-xix 
presidencia de Buchanan (1857-1861). Este modelo revivió la apelación a toda la nación, y a una agenda reformista patriótica. Al demostrar su respeto públicamente por el Congreso, los presidentes Whig obraron dentro de los confines del componente administrativo de la presidencia; salvaguardaron la autoridad presidencial como ya lo hicieran los Federalistas, pero sin hacer grandes alardes públicos de liderazgo ejecutivo.

La importancia que tuvo el siguiente enfoque, identificado con Abraham Lincoln (1861-1865), es incalculable. De hecho, Riccards considera que consistió en un caso sin precedente alguno de mandato presidencial, sin nada que se le pareciera en la historia del Estado de Derecho en Occidente ${ }^{28}$. Debido a la situación extraordinaria de emergencia creada con la Guerra Civil entre estados, Lincoln obró a menudo fuera de la práctica constitucional normal, y en ocasiones, francamente fuera de la ley. De hecho, durante las primeras fases de la guerra y durante los inicios de la reconstrucción, actuó a espaldas y sin la aprobación del poder legislativo. Lincoln presidió un "Estado ejecutivo", asumiendo unos "poderes de guerra" enormes, de una manera que excedió a la de cualquier otra presidencia anterior. Más tarde, sin embargo, su presidencia serviría como modelo a las de Woodrow Wilson (1913-1921), Franklin D. Roosevelt (1933-1945), Harry S. Truman (19451953), Lyndon B. Johnson (1963-1969), y Richard M. Nixon (1969-1974) ${ }^{29}$. Cada uno de estos hombres debió enfrentarse a situaciones extraordinarias, ante las cuales todos ellos pudieron aludir al precedente sentado por Lincoln, de acumulación de poderes extraordinarios en el ejecutivo durante periodos de crisis nacional. El contexto histórico que rodeó a la presidencia de Franklin D. Roosevelt ( FDR»), primero una devastadora depresión económica tanto dentro como fuera del país, y después la Segunda Guerra Mundial, fue tan extraordinario que incluso el tradicional límite de dos mandatos asumidos por cada presidente, en vigor en forma de pacto no escrito desde la presidencia de Washington, se consideró franqueable, y así FDR cumplió tres mandatos completos y llegó a empezar un cuarto. Después de él, sin embargo, el cargo presidencial quedaria limitado oficialmente y legalmente al de dos mandatos de cuatro años cada uno.

Theodore Roosevelt (1901-1909) trajo un espíritu notablemente activista a la presidencia, que más tarde profundizaría FDR. Por ello, el modelo Rooseveltiano que lleva el nombre de ambos, convirtió al presidente en el centro del sistema político, y en la rama más activa del Estado federal. Se puede decir que los dos Roosevelts gestionaron decisivamente la agenda legislativa, reforzando su enfoque con apelaciones directas al pueblo en busca de apoyo. Las famosas «charlas junto al fuego» de FDR constituyeron un método particularmente efectivo de controlar la agenda política, además 
de un uso igualmente hábil del componente de «púlpito privilegiado» del cargo. Los Roosevelts expandieron también la función de bienestar social del gobierno federal en política interna, a la vez que conducían una política externa activa, intervencionista e internacionalista. El modelo Rooseveltiano mostró cómo era una "presidencia imperial» puesta en práctica, al emprender FDR la mayor ampliación jamás vista de competencias del ejecutivo en EE.UU. Sorprendentemente, el pueblo norteamericano toleró esta ampliación, y Roosevelt sigue siendo uno de los presidentes más respetados y mejor considerados ${ }^{30}$.

Ya hemos visto que la Presidencia es un sistema de funciones recíprocas. Se trata de un cargo cuyas competencias aparecen limitadas de forma muy insistente en la Constitución. El Presidente es comandante en jefe de las fuerzas armadas, pero sólo el Congreso puede declarar la guerra. El Presidente puede nombrar altos cargos ministeriales y burocráticos, pero el Congreso puede vetar los nombramientos. El Presidente puede proponer las leyes, pero sólo el Congreso puede promulgarlas. El Presidente puede oponer su veto a la legislación que considere que no sirve a los intereses de la nación, pero el Congreso puede superar ese veto mediante una mayoría de dos tercios. El Presidente puede cambiar el curso de la jurisprudencia a través de su facultad de designar a los nuevos jueces del Tribunal Supremo y del sistema judicial federal, pero una vez nombrados, los magistrados bien pueden fallar en contra del ejecutivo, sin que en teoría al menos, le deban nada al Presidente que les nombró. Todo ello es reflejo del recelo de los Padres Fundadores hacia el poder ejecutivo. También es reflejo de su recelo hacia la democracia popular, y de su fuerte inclinación por un sistema de gobierno democrático representativo, deliberativo y federalista, con contrapoderes que frenasen cualquier posible abuso por parte de un ejecutivo que se extralimitase en sus funciones. El término "sistema» al hablar del sistema presidencialista norteamericano se refiere a la interrelación de poder y autoridad entre las tres ramas del Estado, que deberán trabajar conjuntamente en un esfuerzo de colaboración por conducir a la nación, vigilándose mutuamente por el camino y manteniendo un sano escepticismo hacia la autoridad que colectivamente representan.

Como resultado, la Presidencia ha evolucionado claramente, desde los tiempos de George Washington y los Federalistas, hasta FDR y su presidencia imperial, convirtiéndose en un puesto político con poderes que los constituyentes no pudieron haber previsto. Con cada paso desde el modelo federalista hacia el Rooseveltiano, podemos ver a la Presidencia moviéndose más en dirección al tipo de cargo populista del que los Padres de la Constitución tanto desconfiaban. Lo que ha sucedido con el poder presiden-

${ }^{30}$ RIDINGS y MClver, Rating the Presidents ("Calificando a los Presidentes"). Quizá no sorprenda que los autores califiquen a Lincoln y a FDR como los dos mejores presidentes de la historia de EE.UU. 
cial a lo largo de esta evolución, también provocaría en ellos un profundo escepticismo. En la próxima sección se discutirán los poderes y las limitaciones de la Presidencia refiriéndonos a la desviación del cargo desde las intenciones originales de los constituyentes hacia un modelo populista que ellos hubieran desaprobado.

\section{DE PODERES Y DE LÍMITES: AUTORIDAD PRESIDENCIAL EN EE.UU. ${ }^{31}$}

Cuando los Padres de la Constitución deliberaron y debatieron acerca del cargo de Presidente, fueron cautos respecto a los poderes que le otorgaban, pero también dejaron incompleto su diseño. En aquel momento sintieron correctamente que George Washington sería el primer presidente, y que él establecería el tono presidencial en términos de poder, autoridad, modo de comportamiento, y cumplimiento digno de la tarea, lo que constituiría un modelo perpetuo para todos los futuros presidentes. $O$, dicho de otra forma:

Los constituyentes inventaron una presidencia fuerte pero cuyo poder tenía escasa independencia. Colocaron al Presidente en posición de dirigir (influir, persuadir), pero no en posición de mandar (dar órdenes). ${ }^{32}$

La nueva república que crearon los constituyentes era de un gobierno limitado: todavía los estados poseían gran independencia y capacidad de acción. Se trataba de una república gobernada por el Estado de Derecho, en la que no cabía ningún poder arbitrario o caprichoso en manos del ejecutivo. Era un Estado con separación de poderes, sin duplicación real de tareas entre las tres ramas del Estado. Y era un sistema basado en equilibrios y contrapoderes diseñados para evitar que el poder se concentrase en una sola rama del Estado. Lo que los constituyentes crearon en realidad fue una república deliberativa o negociadora. Todos estos elementos del Estado se establecieron así para fomentar una discusión (negociación) frecuente y áspera entre las tres ramas encargadas de crear un sistema federal efectivo. Ello se hace especialmente evidente en la manera en que regularon el cargo del Presidente.

La Presidencia, tal y como se describe en la Constitución, consiste en un puesto con competencias o poderes formales e informales. Las competencias formales, también llamadas competencias enumeradas, son las ordenadas por la Constitución, como nombrar embajadores, concertar los tratados, o ejercitar los deberes de comandante en jefe. El Presidente tiene también otras competencias formales, llamadas

\footnotetext{
31 Esta sección se basa principalmente en Bennett, The American Presidency, 1945-2000, 1-21, Genovese, The Power of the American Presidency, 1-27; Gregg, The Presidential Republic, 123-216.

${ }^{32}$ Genovese, The Power of the American Presidency, 9.
} 
competencias implícitas, las cuales se deducen de aquellas competencias expresamente otorgadas por la Constitución. Cuando se combinan varias de las competencias enumeradas, se obtienen una serie de competencias resultantes. Finalmente, las competencias informales del Presidente concluyen con las llamadas competencias inherentes, que son las que ha fallado el Tribunal Supremo como derivadas de la existencia de un gobierno nacional. Son aquéllas que no aparecen enumeradas en la Constitución y que dependen de la propia autoridad del Presidente como político. Abarcaría la personalidad que despliegue el Presidente, por ejemplo como líder de su partido político, para moldear la opinión pública con respecto a su programa presidencial, o al interés de la nación acerca de determinados asuntos de política interna o exterior. ${ }^{33}$

Aunque todo este poder puede causar impresión, podemos comprobar esta impresión conociendo las palabras de aquellos que sirvieron como presidentes de los EE.UU. George Washington se sintió, durante el cumplimiento de sus deberes como Presidente, como «un condenado camino del lugar de ejecución». Thomas Jefferson calificó a la Presidencia de «espléndida miseria». Andrew Jackson dijo que era «una condición de esclavitud dignificada». Warren Harding y Harry Truman tildaron a la Casa Blanca, probablemente la residencia más famosa del mundo, de «prisión» y "gran jaula blanca», respectivamente. El 42. presidente de los EE.UU., William Jefferson Clinton, dijo que la Casa Blanca era «la joya de la corona del sistema penitenciario ${ }^{34}$. ¿Cómo era la labor que tenían que desempeñar los moradores del 1600 de la Avenida Pennsylvania, para que tales fueran sus sentimientos?

De nuevo, los ex-presidentes nos dan una visión bastante consistente de los deberes del cargo. George Washington dijo que «Prefiero estar en mi tumba que aguantar otros cuatro años como Presidente». Theodore Roosevelt observó que "cada día, casi cada hora, tengo que decidir sobre cuestiones muy grandes y también muy pequeñas». Dwight Eisenhower se quejó de que «los deberes del presidente son esencialmente interminables. No existe una agenda diaria de tareas que pueda proporcionar un programa completo, ni siquiera una leve idea de las responsabilidades del Presidente. Totalmente al margen de la toma de importantes decisiones, de la formulación de la política a través del Consejo de Seguridad Nacional y del Gabinete, y de la colaboración con el Congreso y con los estados, el presidente tiene ante sí una carga continua de estudio, contemplación y reflexión». Martin Van Buren opinó que "En cuanto a la Presidencia, los dos días más felices de mi vida fueron el de mi entrada en el cargo y el de mi salida del mismo». Herbert Hoover comentó que «Este trabajo no es más

${ }^{33}$ lbid., 9-12.

${ }^{34}$ Ibid., 2-3. 
que un circo múltiple, que incorpora un montón de malos actores. Ni todo el dinero del mundo me convencería para volver a vivir los últimos nueve meses. Las condiciones que hemos experimentado hicieron de esta tarea un verdadero infierno ${ }^{35}$. ¿Qué es lo que provoca unas reflexiones tan amargas acerca de la Presidencia?

De nuevo hemos de volver a las nociones sobre el sistema político diseñado por los constituyentes para apreciar las dificultades del cargo. Los Padres constitucionales desconfiaban del poder ejecutivo, lo que les llevó a crear una Presidencia que era «facilitadora». Por eso la mayoría de los poderes del Presidente quedaron como implícitos, inherentes e informales. Para los constituyentes, el Presidente debía dedicarse a «facilitar» el proceso de representación y deliberación, cuya base central se hallaba en el legislativo. EI Presidente, en esencia, debía iniciar los debates y apuntar la dirección de la discusión que al cabo daría lugar a la legislación y al gobierno efectivo. Para facilitar el proceso, se asumía que el Presidente se comportaría como una parte neutral, situada por encima de las trifulcas y del politiqueo cotidiano de los partidos. De hecho, éste fue el modelo tradicional de la Presidencia durante muchos años. El modelo tradicional de Presidencia consistía en un ejecutivo independiente, distanciado de las pasiones políticas y de los deseos democráticos directos del pueblo. El Presidente tradicional debía ser un administrador (recordemos el elemento administrativo de los deberes presidenciales enumerados en la sección precedente) además de un «facilitador» de la deliberación y del debate políticos. Además, se confiaba en el Presidente para servir como representante nacional del pueblo, pero el pueblo considerado aquí como un órgano político teórico. En parte, el Presidente era la cara pública de este teórico órgano popular, y la única posición responsable ante todo el pueblo por la política nacional. La idea de que el Presidente fuera el representante de todo el pueblo, pero literalmente, resultaba ridícula a los constituyentes, en parte precisamente porque en su esquema, la representación real del pueblo la ostentaba la rama legislativa, el Senado y la Cámara de Representantes. Por eso, salvo las excepciones de Andrew Jackson y Abraham Lincoln, el modelo tradicional de Presidencia fue el modelo par excellence seguido durante los siglos XVIII y XIX. En este sentido, Lincoln sólo puede considerarse atípico, un resultado de las condiciones extraordinarias por las que pasaba una nación en guerra consigo misma, las cuales le llevaron a interpretar y a afirmar la autoridad presidencial de una manera sin precedentes. Por lo demás, Lincoln no era un presidente que buscase deliberadamente hablar por o hacerse amar por el pueblo. Jackson sí que cultivó una imagen de sí mismo como la de un Presidente del pueblo; pero el modelo Jacksoniano provocó una pronta reacción de vuelta hacia la presidencia tradicional (que cabe asociar principalmente con el modelo federalista que establecieron Washington y Adams), el cual siguió siendo la norma durante el resto del siglo XIX.

${ }^{35}$ lbid., 2-3. 
Si consideramos, pues, la Presidencia tradicional como el cumplimiento normativo o "canónico» del cargo de Presidente, entonces la mayoría de los presidentes se enfrentaron a una dura realidad al ocupar el cargo dispuesto según los constituyentes: su poder se veía contestado. Como Bennett ha hecho notar, "Los sucesivos presidentes se han visto acosados por el hecho de que el grado de poder que ejercen es objeto constantemente de oposición, no habiendo un grado normativo de ese poder " ${ }^{36}$. Una vez más, ello se debería a que los constituyentes básicamente diseñaron el cargo a la medida de George Washington, permitiéndole que pusiera su sello personal en el puesto, como modelo para los futuros presidentes. La naturaleza problemática de esa decisión se hace patente sobre todo en la lucha constante entre el Presidente y el Congreso acerca de la extensión y los límites de la autoridad presidencial. Esta lucha es tan inherente a la Presidencia que podemos concebirla como un verdadero elemento definitorio del puesto. Ello nos lleva de nuevo al carácter idiosincrásico de la Presidencia: algunos presidentes se encuentran a sus anchas en un lugar de trabajo con tanta oposición, en tanto que otros naufragan. Cada vez más, se juzga el éxito de cada presidente por su habilidad para ganar en esa lucha por extender la autoridad presidencial, y por evitar reveses que resulten en su disminución.

Antes de entrar a analizar los casos de aquellos presidentes que fueron más influyentes y del impacto que tuvieron respecto al poder del ejecutivo, debemos diferenciar entre poder y autoridad. El poder de la Presidencia, sus competencias, como ya hemos visto, tienen un carácter constitucional, ya sea formal o informal, y limitado. La autoridad del Presidente en cambio es personal. Todos los presidentes que ocuparon el cargo tuvieron el poder presidencial. Es decir, tuvieron la oportunidad de ejercitar las competencias que la Constitución ponía a su disposición. Podían nombrar y destituir, sugerir la política nacional, concertar tratados, hacer la guerra, dirigir la política exterior, establecer programas nacionales, hablar en nombre de la nación, etc. Pero no todos los presidentes tuvieron la autoridad necesaria para ejecutar este poder puesto a su disposición. Sería la autoridad presidencial, el carisma que genera la confianza popular y que se traduce en apoyo político personal, lo que hace posible que algunos presidentes logren ensanchar los límites de sus competencias en nuevas direcciones, ampliando el poder presidencial. A la inversa, la falta de autoridad presidencial merma la labor de muchos presidentes, convirtiéndolos en líderes ineficaces, meros administradores del cargo.

Por ello, si hablamos sólo de poder presidencial, poco más habría que añadir. Como ya hemos visto, la Constitución prescribe aun vagamente las líneas generales del cargo, el cual tiene límites bien definidos tanto por la Constitución como por el Congreso. De ahora en adelante, debemos cam-

\footnotetext{
${ }^{36}$ Bennett, The American Presidency, 1945-2000, 1.
} 
biar la discusión para hablar de la autoridad presidencial. Se trata de esa característica individual que permite que algunos presidentes tengan éxito en expandir su poder presidencial y en ser productivos en términos de sacar adelante una legislación importante, la que tiene que ver con su propia agenda política, consiguiendo su aprobación a pesar de tener al Congreso en la oposición, por estar éste compuesto sobre todo por miembros del otro partido. El presidente republicano Ronald Reagan (antiguo actor), por ejemplo, fue muy efectivo en este aspecto, aunque en otros no fuera un presidente particularmente bueno. La Administración Reagan capitalizó su buena imagen fotogénica, su persona telegénica y sus apelaciones en lenguaje sencillo al pueblo americano, es decir su autoridad presidencial, para favorecer su agenda legislativa conservadora, en medio de un Congreso controlado por los demócratas.

La autoridad es, pues, la variable esencial que determina la habilidad de cada persona en utilizar efectivamente los poderes y competencias propios del cargo. Este hecho implica que, a fin de conocer más a fondo la Presidencia de EE.UU., deberemos de estudiar los «retratos" de algunos de los más influyentes ocupantes del cargo. La Presidencia ha sido tan moldeada por los individuos, es tan idiosincrásica, que tendremos que echar una ojeada a algunos presidentes individuales y examinar su autoridad presidencial si deseamos entender la naturaleza de las competencias y las limitaciones propias del cargo. La obra de Gregg The Presidential Republic tiene una forma útil de estudiar la autoridad presidencial, al definir el cargo como una «institución de representación política» ${ }^{37}$. El Presidente es, en mayor o menor grado, el representante del pueblo americano en temas tanto internos como externos. Se trata, sin embargo, de un esquema recíproco, ya que el grado en el cual el Presidente es representativo dependerá de su propia autoridad popular y política. En última instancia, de acuerdo con Gregg, ello significa que hay dos relaciones clave para la autoridad presidencial: la relación del Presidente con la gente, y su relación con el resto del Estado. Aquel Presidente que tenga una buena relación con el público (tanto dentro como fuera del país), dispondrá de una buena dosis de apoyo a la hora de lidiar con el Congreso, incluso con uno que esté en manos de la oposición. Si la relación del Presidente con el resto del Estado (no sólo con el Congreso sino con toda la Administración pública en general) es buena, de nuevo hay muchas probabilidades de que las iniciativas del Presidente lleguen a ser aplicadas. En resumen, esas dos relaciones serían esenciales a la hora de evaluar la autoridad presidencial, lo que a su vez determina el rumbo que pueda tomar una presidencia en particular, hacia el éxito o hacia el fracaso. Por supuesto, tanto el pueblo como el Congreso de los EE.UU. se sentirán más proclives a aceptar ampliaciones sustanciales del poder del Presidente, si perciben que la persona que está ocupando el cargo en ese momento ostenta una gran dosis de autoridad presidencial.

\footnotetext{
${ }^{37}$ Gregg, The Presidential Republic, preface and 2-7.
} 
Los primeros presidentes, nacidos del molde tradicionalista, generalmente trataron de mantener una distancia de separación eritre la presidencia y el pueblo. Andrew Jackson (1829-1837) ignoró ese modelo original de conducta y cambió drásticamente la naturaleza del poder presidencial, haciendo uso para ello de una autoridad presidencial de raíz popular. Generalmente se considera a Jackson como la figura que introdujo y cultivó el elemento democrático popular en la Presidencia ${ }^{38}$. Jackson fue un gran jefe militar, y tenía ya cierta experiencia como gobernador estatal. Lo que es más importante, la naturaleza de las elecciones de 1828 implicó que Jackson fuera, probablemente, el primer presidente del país en ser elegido verdaderamente a nivel popular. Gracias a su popularidad, fue capaz de transformar la naturaleza de la Presidencia. Jackson reafirmó la faceta de representante del pueblo, y por ejemplo propuso una enmienda constitucional para establecer la elección popular directa del presidente ( $y$ no a través del colegio electoral) en su primer mensaje anual al Congreso ${ }^{39}$. Jackson expandió el poder presidencial al afirmar que la capacidad de designar y de destituir estaba investida en el Presidente y no requería del consejo ni del consentimiento del Congreso. El Congreso tan sólo debía fiscalizar, pero no ordenar ni participar de ningún otro modo, en lo que era un derecho del Presidente a seleccionar su propio Gabinete, sus ministros, y demás cargos de designación propia.

Sobre todo, la autoridad política de Jackson derivada de su popularidad, le permitió ampliar grandemente el poder de la Presidencia mediante su uso frecuente del veto presidencial. Esta facultad formal del Presidente había sido poco utilizada hasta entonces. Su uso se creía tradicionalmente que debía reservarse para la legislación que fuera inconstitucional. Jackson empleó su facultad de veto más que los seis presidentes anteriores juntos. Para él, el veto presidencial era una herramienta política, y no una mera salvaguarda de la Constitución. Así, Jackson vetó un proyecto de ley que renovaba la escritura de un banco. Un historiador presidencial ha considerado ese suceso como "el veto más importante jamás emitido por un presidente» ${ }^{40}$. Se trata de un hecho crucial en la revisión de la autoridad presidencial, y por ello merece una inspección más detallada.

El Congreso aprobó un proyecto de ley que renovaba la escritura o carta de privilegio del «Second Bank of the United States», en 1832. El privilegio de este banco no expiraba hasta 1836, pero los congresistas que lo apoyaban no querían esperar y arriesgarse a perder la votación en un futuro

\footnotetext{
${ }_{38}$ Esta sección sobre Jackson procede de: Bennett, The American Presidency 1945-2000, 7; Genovese, The Power of the American Presidency, 16-19, 58-63; Gregg, The Presidential Republic, 81-85; Riccards, The Ferocious Engine of Democracy, 115-143; Ridings and Mclver, Rating the Presidents, 48-55.

${ }^{39}$ Gregg, The Presidential Republic, 81.

${ }^{40}$ Roger Remini, Andrew Jackson and the Course of American Freedom, 1822-1832, 369, citado en Gregg, The Presidential Republic, 81 .
} 
Congreso. Jackson despreciaba a los bancos nacionales, por considerarlos monopolios financieros establecidos en beneficio de los ricos y en detrimento de los trabajadores más pobres. Inmediatamente emitió su veto al proyecto y, al hacerlo, en combinación con su despido del Secretario del Tesoro y con su retirada de los depósitos federales de los bancos nacionales sin contar con la aprobación del Congreso, suscitó las iras del Senado, que atacó la actuación del Presidente. Aunque incapaces de superar el veto presidencial, varios Whigs destacados y sus aliados de otros partidos, encabezados por Daniel Webster, Henry Clay, y John C. Calhoun, se opusieron abiertamente al derecho de actuar de esta forma del Presidente Jackson, pensando que se había extralimitado y de paso había usurpado competencias del Congreso.

Básicamente, Webster y sus aliados se basaban en sus ideas preconcebidas acerca de los límites del poder presidencial, así como en la visión tradicional del papel del Presidente en el gobierno. Para ellos, la representación ejercida por la Presidencia no podía ser función de la popularidad de una sola persona concreta cumpliendo el papel de representante del inmenso pueblo americano. En su opinión, un Estado republicano por definición implicaba que el centro de la autoridad y del gobierno radicase en el legislativo elegido popularmente. La función de representar al pueblo la cumplía el Congreso mediante sus deliberaciones acerca de la legislación, y no el ejecutivo con su activismo. Para ellos, la entidad que representaban -el pueblo- era demasiado diverso, demasiado extenso, como para poder ser representada por una única persona. Solamente un órgano legislativo elegido a nivel local, con la diversidad de estados y de regiones bien representada, podía en su caso aspirar a representar realmente al pueblo. El ejecutivo era representante tan sólo de una masa informe, ambigua, de ámbito nacional; el pueblo de EE.UU. en su sentido más teórico, más amplio y menos cohesionado. En fin, su histórica desconfianza hacia el poder ejecutivo asomaba en su creencia de que la libertad y el buen gobierno del pueblo se alcanzarían del mejor modo mediante el complejo sistema de poderes separados, tal y como los constituyentes lo habían diseñado. La antítesis de ese diseño del Estado, era de hecho la creencia en la validez de la representación centrada en un solo individuo, tal y como Jackson aparentemente trataba de defender. ${ }^{41}$

Posiblemente, Jackson no podía haber concebido la Presidencia y su propio papel de manera más opuesta. Jackson, que accedió al cargo en 1832 tras una victoria electoral arrolladora, sintió que ello le otorgaba un mandato del pueblo en calidad de su representante directamente electo. Su argumento fue que «El Presidente es el representante directo del pueblo americano ${ }^{42}$. Recordó que el Senado, que era el que estaba organizando esta protesta, era un órgano responsable ante los estados, y sólo indirecta-

\footnotetext{
${ }^{4}$ Gregg., The Presidential Republic, 84-94.

42 lbid., 83.
} 
mente ante el pueblo. De nuevo, Jackson invocaba un argumento basado en el apoyo y en la representación popular. El presidente, en su opinión, representaba a la totalidad del pueblo, y no sólo al de un estado, condado, población o ciudad en particular. $Y$ con respecto al proyecto bancario y a su propio veto, Jackson aparecía como contrario a los poderosos intereses financieros y a sus defensores dentro del Estado de EE.UU., en nombre de los ciudadanos ordinarios del país. En verdad, en su opinión él estaba actuando de acuerdo con su juramento presidencial de proteger y defender los intereses del país tal y como aparecen expresados en la Constitución. Este enfoque novedoso de Jackson acerca dela función del Presidente supuso una revolución en las concepciones del poder presidencial y de sus límites. En efecto, FDR, otro revolucionario sucesor en el ejecutivo norteamericano, escribió de Jackson:

Una proporción abrumadora del poder fáctico de la nación se le opuso. Los medios principales de difusión de la información y de caldeado de la opinión pública le combatieron. El intelectualismo vanidoso y estéril le criticó. El tradicionalismo hueco y rancio le señaló con su dedo tembloroso - todos excepto el pueblo de los Estados Unidos. ${ }^{43}$

La Presidencia de Jackson puede verse como el primer intento de desviarse de una política elitista en favor de una concepción más popular acerca del verdadero electorado de un Presidente. Sus apelaciones directas al pueblo en busca de apoyo implicaron a la gente en el desarrollo de una conciencia nacional a la hora de hacer política. En su percepción de su propia elección al cargo, y de la responsabilidad que esa elección le confería, podemos observar el primer esfuerzo real por establecer lo que presidentes posteriores llamaron un «mandato» o comisión electoral. Debido a su creencia en ese mandato, Jackson se sintió imbuido de una enorme autoridad presidencial. Para Jackson, como para futuros presidentes, este mandato podía servir como base para que el Presidente desafiara la tradicional preponderancia del Congreso en la vida política y en la agenda legislativa de la nación. Estos planteamientos sentaron precedentes que, si bien no fueron empleados a fondo por los sucesores inmediatos de Jackson, a la postre resultarían muy influyentes en la evolución del cargo, y serían bien conocidos por parte de casi todos los presidentes posteriores.

Andrew Jackson y Abraham Lincoln fueron los dos presidentes más notables del siglo XIX en cuanto a influencia en la evolución de la Presidencia. Pero cabe considerar a la presidencia de Lincoln como anómala a causa de sus circunstancias históricas extraordinarias. Ningún Presidente anterior o posterior ha debido enfrentarse a un doble reto tan grave como el que le plantearon a Lincoln la Guerra de Secesión, una amenaza a la unidad políti-

\footnotetext{
${ }^{43}$ Ridings and Mclver, Rating the Presidents, 49.
} 
ca del país, y la abolición de la esclavitud, una amenaza a la unidad social del país. El primero, la Guerra Civil Americana, constituyó una situación que requería del ejecutivo un poder ágil, diligente y sin trabas, lo que sería un modelo muy importante para futuros presidentes. Por lo demás Lincoln, para eterna gratitud de sus compatriotas, supo estar a la altura de las circunstancias, y por ello se le suele considerar como el mejor presidente que han tenido los EE.UU ${ }^{44}$. Sin embargo, los futuros presidentes no podrán, ni tampoco lo querrian, contar con unas circunstancias históricas tan dramáticas como las suyas para extender el poder presidencial mediante el ejercicio de su autoridad presidencial. En tal caso, creo, la presidencia de Jackson seguirá siendo su modelo operativo, ya que representa un escenario más probable y frecuente al que enfrentarse en la realidad - el de la simple oposición de poderes entre las ramas ejecutiva y legislativa del Estado.

El asesinato de Lincoln se vio seguido de una retahíla de presidentes poco interesantes. El modelo tradicional de la Presidencia pareció haberse reinstaurado, y de nuevo el predominio del Congreso fue la norma en el Estado norteamericano, hasta que llegó la elección de William McKinley (18971901). La presidencia de McKinley coincidió con el ascenso de EE.UU. como potencia internacional emergente. McKinley no fue un presidente especialmente brillante, pero la Guerra Hispanoamericana de 1898 ocurrió bajo su mandato. Reacio al principio a introducir a los EE.UU. en una política internacional belicista, McKinley se vio sin embargo forzado a entrar en guerra debido a la presión popular, que respondía a la movilización de masas por parte de una prensa populista y patriotera. Los EE.UU. ganaron la guerra en pocos meses con una pérdida mínima de vidas norteamericanas. La victoria fue tan rápida que instantáneamente los EE.UU. se convirtieron en una potencia mundial, adquiriendo además varias colonias en ultramar. En una época de aspiraciones imperiales que abarcaban a casi todo el globo, la posesión de colonias confería prácticamente el estatus de gran potencia. Poco después, McKinley ganaba una victoria aplastante en las elecciones presidenciales de 1900, por lo que pudo reclamar de nuevo para sí ese «mandato electoral» del que Jackson había disfrutado sesenta y ocho años antes.

Sin embargo, la importancia de la presidencia de McKinley fue que alteró la dinámica política de autoridad y preponderancia del Congreso, y lo hizo quizá para siempre. Michael Genovese resume así este cambio:

Dirigió una guerra presidencial, prácticamente por su cuenta, reclamando a tal fin toda la autoridad; adquirió las Filipinas (usando para ello de un Acuerdo Ejecutivo, puenteando así al Senado); entre él y su Secretario de Estado John Hay, establecieron una política de Puertas Abiertas hacia China; en 1900, sin contar con la aprobación del Congreso, despachó 5.000 soldados a China para suprimir la

44 Ibid., 104 y Genovese, The Power of the American Presidency, 20. 
Rebelión de los Bóxer. Así, yendo a la guerra, actuando unilateralmente, puenteando al Congreso, estableciendo un imperio, $y$ al hacerlo basado «únicamente» en la autoridad del ejecutivo, McKinley alteró el equilibrio de poderes (especialmente en el ámbito exterior) a favor de la presidencia. ${ }^{45}$

McKinley recibió dos disparos mientras asistía a la Exposición Panamericana en Buffalo, Nueva York, el 6 de septiembre de 1901, muriendo una semana más tarde a causa de las heridas. Aunque el esfuerzo en aras de explotar su autoridad presidencial se vio así truncado, el impacto de McKinley sobre la Presidencia resulta destacado por varias razones. Primero, demostró que una guerra culminada con éxito podía traducirse en un «mandato popular» de estilo Jacksoniano, lo que facilitaba la ampliación del poder presidencial. - Aquí podríamos estar tentados de recordar la experiencia de Lincoln en conducir la Guerra Civil a una conclusión satisfactoria, al reunificar el país. Pero la experiencia de Lincoln es difícil de extrapolar, porque la Guerra Civil fue un asunto interno de americanos contra americanos, y por ello la victoria constituyó un hecho agridulce. Sólo los oportunistas presidenciales más crudos se referirían a la conclusión de la Guerra Civil como satisfactoria. El país volvía a estar unido, pero a un precio exorbitante en cuanto a vidas humanas y con unas consecuencias a corto y a largo plazo que mal pueden calificarse de satisfactorias-. En segundo lugar, la necesidad de una toma de decisiones inmediata en época de guerra constituía una razón poderosa y legítima para sortear las limitaciones del Congreso sobre la acción presidencial. Tercero, la política exterior se estaba convirtiendo en asunto crucial dentro de la expansión del poder presidencial, un área en la que el Presidente disponía de competencias importantes tanto enumeradas como implícitas. Finalmente, en el modelo Jacksoniano, el pueblo podía aportar un poderoso apoyo extra-estatal a la Presidencia, especialmente a la hora de evitar la autoridad del Congreso, con tal de que percibiera que el Presidente estaba obrando en favor de su interés (léase en interés de la nación).

El asesinato de McKinley trajo al poder a su dinámico vicepresidente, Theodore Roosevelt (1901-1909). Como ya hemos dicho antes, la Presidencia es una posición política en la que cuenta la idiosincrasia, y en la que el poder aumenta y disminuye al compás de las energías de las personas que la ocupan. La energía desplegada por Theodore Roosevelt superó a la de cualquier otro presidente anterior; y, quizá, su presidencia no haya sido igualada en cuanto a su deseo personal por convertir el cargo en un vehículo poderoso con el cual hacer realidad sus ambiciones para el país. Heredero directo de Jackson en transformar la Presidencia en un cargo popular, usó a menudo de su «púlpito privilegiado» para la persuasión y el liderazgo presidencial ${ }^{46}$. El ascenso de EE.UU. como potencia mundial, explotado a duras penas por McKinley, constituyó una oportunidad preciosa para Roosevelt,

${ }^{45}$ Genovese, The Power of the American Presidency, 108.

${ }^{46}$ Ibid., 109. 
que no la dejó escapar. Conscientemente, como Jackson hiciera antes de él, trató de darle una nueva forma a la Presidencia:

Hice y ordené hacer muchas cosas que ningún Presidente ni ningún jefe de departamento habian hecho antes. No usurpé el poder, pero sí que amplié enormemente el uso del poder ejecutivo. En otras palabras, actué por el interés general, obrando en favor del bien común de todo nuestro pueblo, de cualquier manera que fuese necesaria, salvo que me lo impidiese una prohibición directa de la Constitución o del legislativo. ${ }^{47}$

Roosevelt era un oportunista, pero que reconocía el significado de su circunstancia histórica: «Si no existe la gran ocasión, no tienes al gran estadista; si Lincoln hubiera vivido en tiempos de paz, ahora nadie conocería su nombre ${ }^{48}$. Claramente percibía que las épocas extraordinarias ayudan a hacer presidentes extraordinarios. Sabía también que su propio tiempo no era extraordinario. Por ello, trabajó con especial tesón para dejar su impronta sobre la Presidencia y sobre el país durante aquel periodo de relativa paz doméstica y exterior. Su mandato fue testigo de una notable continuación en el ascenso de EE.UU. al estatus de potencia mundial militar e industrial. Roosevelt estaba resuelto a dejar su marca en aquella oportunidad histórica de cambios que tenían lugar en los EE.UU. de principios del siglo XX, pese al «hándicap» de tratarse de tiempos ordinarios.

Igual que Jackson, cultivó conscientemente esa conexión suya con el pueblo, y su propio papel como servidor de los deseos constitucionales y democráticos de éste. Esta vinculación de la Presidencia al pueblo que Jackson iniciara, era tenida por muchos como inapropiada. Recordemos el modelo tradicional de la Presidencia, y los recelos de los constituyentes hacia las pasiones populares y la propensión al populismo y la demagogia. Pero Roosevelt ignoró esa prohibición, considerándola como una reliquia del siglo XVIII que ya no valía para las demandas del país en el siglo XX, ni para su concepción de la Presidencia, cuyo liderazgo creía necesario. Milkis y Nelson, politólogos, han escrito sobre Roosevelt:

Esta teoría de Roosevelt de considerar al ejecutivo como "servidor», sin embargo, requería del establecimiento de una conexión popular más fuerte. Por ello, en diversas ocasiones TR apeló directamente al pueblo, para presionar a miembros del Congreso y lograr así que apoyasen sus políticas. ${ }^{49}$

Roosevelt reconoció que se podía emplear este apoyo popular en favor del Presidente a la hora de enfrentarse a un Congreso recalcitrante; él, más

${ }^{47}$ Ibid., $110-111$.

${ }^{48}$ lbid., 111.

${ }^{49}$ Milkis y Nelson, The American Presidency, 209, citado en Genovese, The Power of the American Presidency, 113. 
que ningún otro presidente anterior, consideró conscientemente a su pueblo como su aliado.

Theodore Roosevelt expandió el poder presidencial con la autoridad conferida en él por la combinación de la Constitución y del pueblo. En asuntos internos fue un activista, con su llamado "Contrato Cuadrado", ("Square Deal") su nueva legislación anti-monopolística con la Ley «Hepburn Act», y su introducción de la conservación del medio ambiente al abrir el primer parque natural del país. Creó el Departamento de Comercio y Empleo como parte de su agenda doméstica, que es demasiado larga para enumerar aquí. Cuando Roosevelt ordenó la intervención militar en Santo Domingo, en 1904-1905, subrayó una vez más la independencia del ejecutivo para actuar siempre que los intereses norteamericanos estuvieran amenazados o a punto de serlo. Más aún, cuando el Senado no ratificaba algún tratado negociado por él, ignoraba sus objeciones y lo aprobaba él mismo por vía ejecutiva, haciendo notar que «La Constitución no me concede la competencia explícita de celebrar este tratado necesario con Santo Domingo. Pero la Constitución tampoco me prohíbe hacerlo ${ }^{50}$. Este es sólo un ejemplo de la dirección por Roosevelt de la política exterior de EE.UU. durante su mandato. Impulsó también el crecimiento de la marina, dirigió las negociaciones que desembocaron en la construcción del Canal de Panamá, y presidió las conversaciones de paz que acabaron con la Guerra Ruso-japonesa. Como resultado de esos esfuerzos suyos de mediación, Roosevelt fue el primer presidente de los EE.UU. en recibir el Premio Nobel de la Paz.

Roosevelt transíormó drásticamente la Presidencia mediante esta extensión por su parte de los poderes del cargo en las esferas interna y externa. Pudo hacerlo así por la fuerza de su personalidad y por su popularidad entre el gran público, todo lo cual le confirió una gran dosis de autoridad presidencial. Las citas siguientes sirven para compreder las nociones de Roosevelt acerca de la Presidencia y de su función como presidente:

Mientras fui presidente, lo he sido, con todo mi énfasis; he utilizado cada gramo de poder que me proporcionaba el cargo, y no me importaron nada las críticas de aquéllos que hablaban de mi 'usurpación del poder'... Creo en un ejecutivo fuerte; creo en el poder. ${ }^{51}$

Ningún Presidente disfrutó tanto siéndolo como yo disfruté, y por eso no conozco a ningún hombre de mi edad que se lo haya pasado tan bien..." 52

Una visión tan expansionista de la Presidencia por supuesto no dejaba de presentar problemas. Este poder y esta autoridad recién ampliados por Roosevelt se podían utilizar para hacer el bien, pero ¿qué salvaguardas te-

\footnotetext{
so lbid., 114.

${ }^{51}$ Ridings and Mclver, Rating the Presidents, 166.

${ }^{52}$ Genovese, The Power of the American Presidency, 115.
} 
nemos para evitar que otros presidentes los utilicen para mal? También, esta Presidencia de apoyo popular defendida por Roosevelt suscitaba dudas de hasta dónde podría llegar el jefe del ejecutivo de la nación con el fin de ganarse y mantener el favor popular. De hecho, el manejo por parte de Roosevelt del Asunto de Brownsville en 1906 suscitó exactamente este tipo de recelos, además de arrojar una sombra de duda de comportamiento racista durante sus últimos años como presidente ${ }^{53}$. Al final, Roosevelt engrandeció las competencias formales e informales de la Presidencia, haciendo posible para el cargo asumir el reto de gobernar un país mucho más poblado, dinámico y reconocido internacionalmente que el que conocieron los Padres de la Constitución allá en 1789, y un país que en su opinión necesitaba un ejecutivo fuerte. Roosevelt, básicamente, preparó a la Presidencia para el siglo veinte, dotándola de nuevas vías que sus sucesores pudieron más tarde explotar a fondo.

Curiosamente, quien fuera sucesor inmediato de TR en el cargo, William Howard Taft (1909-1913), no compartió el mismo punto de vista sobre la Presidencia. Por el contrario, Taft pensó que Roosevelt había ampliado el poder del ejecutivo de manera peligrosa, y que las competencias del Presidente debían venir tasadas de forma específica «o bien en la Constitución o mediante una ley del Congreso aprobada conforme a aquélla. Pero no hay ningún residuo indefinido de poder que pueda ejercitar porque le parezca que es de interés público " ${ }^{54}$. Taft supuso un paso atrás en términos de poder presidencial, y probablemente perdería la popularidad de la mayoría de los norteamericanos al saberse que fue él quien presidía el país durante la aprobación de la 16. ${ }^{\text {a }}$ enmienda a la Constitución, la cual dio al Congreso la posibilidad de establecer un impuesto sobre la renta.

Otro beneficiario de! modelo presidencial Jacksoniano, y revisionista del modelo de Roosevelt, fue el 28. presidente de EE.UU., Woodrow Wilson (1913-1921). Wilson fue sin duda quien más había estudiado de todos los ocupantes del Despacho Oval, pues había ganado un doctorado (Ph.D.) en la Universidad Johns Hopkins. Había sido también rector de la Universidad de Princeton, además de gobernador de New Jersey, antes de asumir el cargo de Presidente. Wilson ya había meditado y escrito acerca de la Presidencia en 1885, año en que publicó su primer libro, Congressional Government. En este libro criticó tanto a la Constitución como a los constituyentes por haber creado un sistema que hacía muy difícil gobernar el país con eficacia. Él

${ }^{53}$ Ridings and Mclver, Rating the Presidents, 165. La severidad mostrada por Roosevelt durante el 'caso Brownsville', en el que se acusó a unos soldados de color de disparar en el pueblo de Brownsville, Texas, levantó la sospecha de que estuviese cortejando a los votantes blancos sureños, dándoles la razón con respecto al 'problema Negro' en EE.UU. La investigación interna del ejército no logró esclarecer los hechos, pese a lo cual Roosevelt ordenó la expulsión perpetua con deshonor del ejército de los 160 hombres implicados.

${ }^{54}$ Genovese, The Power of the American Presidency, 116-117 
veía al Presidente, en aquella época, como un simple gestor y no como un dirigente nacional y político. Si embargo, en 1900 revisó su obra y comenzó a concebir este cargo de forma diferente:

Cuando los asuntos exteriores jueguen un papel importante en la política y en la vida diaria de la nación, su Ejecutivo debe necesariamente ser su director: debe emitir todo juicio inicial, dar cada primer paso a la hora de actuar, suministrar la información en base a la cual debe actuar, proponer y en gran medida controlar su conducción. El Presidente de los Estados Unidos se halla hoy, desde luego, al frente de estos asuntos. ${ }^{55}$

Si bien Wilson reconocía la preeminencia presidencial en asuntos exteriores, retomando así un legado que le llevaba hasta la propia Constitución y sus diseñadores, ¿qué ocurría con los asuntos internos? ¿Qué sucedía con esa nueva relación, entablada por Jackson, y que Roosevelt había forjado entre el pueblo de EE.UU. y su Presidente?

Wilson, igual que Roosevelt, creía en un Presidente fuerte, dinámico y capaz de dirigir. Una nación fuerte, vital y en pleno crecimiento necesitaba tener al frente a un líder, no a un gestor. A tal fin, Wilson revisó otra vez sus ideas iniciales acerca de la presidencia, y comenzó a recopilar una serie de conferencias que acabaron publicadas en 1908 como otro libro llamado Constitutional Government in the United States. He aquí un extracto del mismo que delimita claramente su visión acerca del cargo. Nótense las similitudes con las ideas de Roosevelt, pese a la extensión lógica dada por Wilson a estos pensamientos:

[El Presidente se concibe ahora] como la fuerza unificadora de nuestro complejo sistema.

[La suya] es la única voz nacional en nuestra política diaria. Dejémosle ganarse una vez la admiración y la confianza del país, y no habrá ninguna otra fuerza que se le oponga ... Si consigue interpretar el espíritu nacional y persiste en defenderlo sin miedo, será irresistible; el país nunca siente tanto entusiasmo por la acción como cuando su Presidente posee esa visión y esa fuerza. Su instinto le pide una acción unificada, y sus ansias son tener un único líder.

[El cargo de Presidente] es lo que con fuerza y sagacidad él mismo sepa hacer de él.

La Constitución le pide que hable, y los tiempos de crisis y de cambio arrojan más y más sobre su cargo la tarea de originar toda política. El suyo es el lugar vital de acción dentro del sistema. ${ }^{56}$

\footnotetext{
${ }^{55}$ lbid., 119.

${ }^{56}$ Ray Stannard Baker, Woodrow Wilson, London: Heineman, 1932; Arthur Walworth, Woodrow Wilson, New York: Norton, 1978; Kendrick A. Clements, The Presidency of Woodrow Wilson, Lawrence: University Press of Kansas, 1992; August Heckscher, Woodrow Wilson, New York: Collier, 1991; todos ellos citados en Genovese, The Power of the American Presidency, 119.
} 
Wilson había comprendido los cambios que estaban teniendo lugar en el país y los que habían tenido lugar en su sistema político. Ya no se trataba de que el Presidente fuera un mero administrador; el contexto histórico del país y el de su cargo más elevado habían cambiado tanto que el Presidente ya no podía actuar sólo como un administrador esperando así dirigir efectivamente el país. Para Wilson parece que no había opción. El Presidente de los EE.UU. debe liderar. Como para subrayar esta creencia, Wilson fue el primer presidente desde John Adams en dirigirse en persona en una sesión especial al Congreso, comenzando así esa tradición larga y continuada de que el Presidente dirija un discurso sobre el estado de la Unión cada año. ${ }^{57}$

El primer mandato de Wilson estuvo marcado por su vigorosa agenda interna de política reformista conocida como la «Nueva Libertad». Este programa legislativo incluyó la aprobación de leyes anti-monopolio, iniciativas de apoyo a los sindicatos, rebaja de aranceles, y leyes sobre el trabajo de los menores. Wilson creó también la Reserva Federal, que ha sido hasta nuestros días el organismo económico más influyente del país. Pero no toda la agenda de Wilson fue tan progresista: también emprendió políticas que permitían la segregación en la Administración, y no impidió una represión interna masiva de los afro-americanos durante la Primera Guerra Mundial. De nuevo, cabe reconocer aquí el peligro de una Presidencia demasiado atada a la opinión pública nacional, algo que los constituyentes vislumbraron con preocupación.

El exitoso primer mandato de Wilson y su promesa de que los EE.UU. no intervendrían en la guerra europea le allanaron el camino para una fácil reelección. No pudo, sin embargo, mantener a los EE.UU. fuera de la guerra; y sin duda vio en ello la oportunidad de acrecentar el poder de la nación y el del Presidente. Aquí tenemos a un Wilson obrando como había pensado y escrito que un presidente debía obrar: como el portavoz político nacional. Además, durante su segundo mandato, el escándalo del Jefe de Correos puso a prueba el derecho del Presidente de designar y destituir al personal dentro del Estado. Wilson habia nombrado a Frank S. Myers como Jefe de Correos en 1917, pero en 1920 le solicitó que presentase su dimisión. Myers se negó, y recurrió ante los tribunales su retirada del cargo, utilizando una ley del Congreso de 1876 como base, dado que Wilson no había contado con la participación del Congreso para sus nombramientos. El caso llegó al Tribunal Supremo, el cual falló a favor del Presidente, argumentando que los constituyentes ya habían debatido este asunto y le habían otorgado la facultad de nombramiento al Presidente en $1787^{58}$. La victoria de Wilson fue consecuente con su manera de entender la Presidencia: el Presidente es el dirigente de la nación, y no representa intereses partidistas, sino que interpreta el espíritu nacional haciéndolo público y programático, tal y como sugiere este extracto procedente de un discurso de su campaña de 1912:

${ }^{57}$ lbid., 120.

${ }^{58}$ lbid., 120 
A menudo he pensado que la única fuerza de un hombre público reside en el número de personas que están de acuerdo con él; y que la única fuerza que un hombre puede mostrar, y de la cual enorgullecerse, consiste en que muchos de sus conciudadanos confían en él, y están listos para seguirle. Pues la función de un dirigente del Estado es escuchar lo que la nación está diciendo, y conocer lo que le está sucediendo. Su tarea no es juzgar por la nación sino a través de la nación, siendo su portavoz. ${ }^{59}$

Por desgracia para Wilson, el pueblo de EE.UU. no aceptó un liderazgo presidencial fuerte si ello significaba perder un gran número de vidas en una guerra extranjera. Wilson había prometido quedarse al margen de la guerra en Europa. Pero la oportunidad que la guerra presentaba para acrecentar el poder nacional y presidencial debió resultarle demasiado tentadora. Aunque las bajas norteamericanas fueron pequeñas comparadas con las de los beligerantes europeos, los norteamericanos no pudieron aceptar la pérdida de vidas humanas, la mayor sucedida desde la Guerra Civil. Wilson calculó mal su autoridad presidencial, lo que unido a la promesa incumplida y a su poca disposición para el compromiso, provocó una fuerte reacción contra su liderazgo. A diferencia de Roosevelt, quien cultivara una imagen como hombre del pueblo, Wilson con su comportamiento parecía estar indicando que se encontraba por encima del pueblo. Wilson emprendió una gira tortuosa por la nación destinada a promover el tratado de paz de Versalles (junto con sus dos iniciativas, los Catorce Puntos y la Sociedad de naciones) y esperando obtener así el apojo popular, lo que redundaría en una ratificación por el Congreso. Al final, Wilson sólo consiguió caer gravemente enfermo, lo que resultó en la cancelación de la gira y en su propia incapacitación como jefe del ejecutivo, amén de ver rechazada su política. ${ }^{60}$

Podría pensarse que Wilson fracasó, pero de hecho había conseguido continuar con el fortalecimiento de la Presidencia iniciado por Theodore Roosevelt, especialmente en lo que respecta a la dirección política y al intervencionismo en la legislación interna. Demostró el potencial de seguir arrastrando a la gente hacia la política y el gobierno. Durante su primer mandato, Wilson fue un líder de éxito entre la gente, en su propio partido, y en la diplomacia de la nación, ahondando con ello en el curso emprendido por Roosevelt. Juntos, Roosevelt y Wilson le dieron a la Presidencia un rumbo que ya nunca abandonaría. En el futuro, los presidentes podrían optar por no seguir el modelo activista y no hacer uso de todo el espectro de poder presidencial a su disposición; pero que ese modelo era posible, y tal poder disponible, eso ya no se discutiría más.

\footnotetext{
${ }^{59}$ Charles R. Kesler, "Woodrow Wilson and the statesmanship of Progress", en Thomas R. Silver and Peter W. Schramm, eds., Natural Right and Political Right, Durham, NC: Carolina Academic Press, 1984, 123, citados en Gregg. The Presidential Republic, 100.

60 Bennett, The American Presidency, 1945-2000, 15-17; Genovese, The Power of the American Presidency, 120-121.
} 
Tres presidentes republicanos de muy poco relieve siguieron al demócrata Wilson en el cargo. Warren G. Harding (1921-1923) murió en el cargo tras haber dirigido una administración plagada de corrupción. Calvin Coolidge (1923-1929) hizo poco, pero por lo menos no fue un corrupto ${ }^{61}$. Ambos pueden considerarse en términos de una reacción general de moderación frente al liberalismo doctrinario y fuerte activismo de Wilson. No es que se reviviera el modelo tradicional de la Presidencia, pero ninguno de los dos hizo nada por utilizar o expandir los amplios poderes que ahora poseía la Presidencia. Herbert Hoover (1929-1933) sucedió a Harding y a Coolidge. Hoover fue víctima de las circunstancias históricas desgraciadas, además de la mala gestión económica de Coolidge: nueve meses después de haber jurado el cargo, tuvo lugar el crack bursátil, dando paso a la Gran Depresión. Recordemos que Theodore Roosevelt dijo que las épocas extraordinarias dan lugar a presidentes extraordinarios: Hoover no fue capaz de estar a la altura de esta ocasión que la historia le presentaba. No hizo intento alguno de emplear los poderes a su cargo para detener la caída en espiral de la economía del país. Por desgracia, Hoover se vio desbordado por los hechos, y cuando en las siguientes elecciones tuvo que enfrentarse al ex-gobernador de Nueva York, el demócrata Franklin Delano Roosevelt, obtuvo la mayor derrota jamás recibida por un ocupante del cargo de presidente de EE.UU. ${ }^{62}$

Franklin Delano Roosevelt ( «FDR»), como su primo lejano Theodore Roosevelt, era un firme partidario del activismo del ejecutivo. Procedía de una familia acomodada, habiéndose licenciado en Historia en Harvard. Comenzó su carrera política al ser elegido para el Senado del estado de Nueva York en 1910. La continuó al ser nombrado vicesecretario de la Marina en 1913. Fue candidato a vicepresidente en la candidatura para la Presidencia de James M. Cox eri 1920, derrotada sin embargo por Warren G. Harding. FDR contrajo la polio en 1921 y perdió el uso de las piernas. Su carrera pública parecía acabada, pero FDR se tomó muy en serio la rehabilitación, mantuvo sus contactos políticos, y reapareció en la convención demócrata de 1924, haciendo el discurso de nominación del candidato presidencial. Ganó después las elecciones para gobernador de Nueva York en 1928, emprendiendo un programa de reformas progresistas, adelanto de lo que vendría después como presidente, el cual implantó un programa de subsidios estatales, un seguro de desempleo, y puestos de trabajo relacionados con obras públicas, tras el desastre de la depresión económica en 1930. Para 1932, FDR estaba ya preparado para ser candidato a la Casa Blanca. ${ }^{63}$

\footnotetext{
${ }^{61}$ Bennett, The American Presidency, 1945-2000, 17-19; Genovese, The Power of the American Presidency, 122-128.

${ }^{62}$ Ridings and Mclver, Rating the Presidents, 195.

${ }^{6}$ Toda esta información biográfica y política sobre FDR deriva de: Ridings and Mclver, Rating the Presidents, 196-205; Bennett, The American Presidency 1945-2000, 17-21; Genovese, The Power of the American President, 130-139; Gregg, The Presidential Republic, 160-162.
} 
FDR le ganó las elecciones a Hoover con la promesa de una acción presidencial. Dejó muy claro que no repetiría el modelo republicano de inactividad en el frente interno, terminando posteriormente también con el aislamiento diplomático. Suele considerársele como el primer presidente moderno, además de autor de la mayor expansión de competencias presidenciales tanto internas como internacionales que haya visto el cargo en toda su historia. Tras su paso por la Presidencia, no cabía ya la posibilidad de retorno al modelo republicano. Todos los presidentes después de él han sufrido para bien o para mal la comparación con la actuación que llevó a cabo FDR. Se le tiene generalmente por el presidente más importante del siglo XX y, junto con Abraham Lincoln y George Washington, por uno de los mayores presidentes de toda la historia de EE.UU. Por eso puede verse en él el epítome tanto del poder como de las limitaciones que tiene el cargo, y en ese sentido cabría considerarle como el presidente más influyente que ha tenido el país. Ninguno después de él ha sido capaz, no ya de superar sino siquiera de igualar, el grado de ampliación de poder o de ejercicio de autoridad presidencial que desplegó FDR.

La presidencia de FDR fue tan larga y sus medidas políticas tan numerosas, amplias y variadas que sería inútil en este artículo tratar de explicarlas todas. Haré pues un resumen de su presidencia, dividido en las áreas de: política interna, política exterior, relación con el Estado, relación con el pueblo, e impacto sobre la institución presidencial contemporánea. Para aquellos que deseen estudiar con mayor detalle esta presidencia, en la siguiente nota a pie de página proporciono una breve bibliografía acerca de FDR. ${ }^{64}$

El programa de medidas de FDR en el frente interno fue extraordinario desde el principio. Frente a la inactividad que había caracterizado a las tres presidencias anteriores, FDR estaba resuelto a arrancar con un curso dinámico de actuación, que en su opinión resultaba necesario para sacar al país rápidamente de la Depresión. En su primer año en la Casa Blanca, inundó el Congreso con proyectos que suponían el lanzamiento de un vasto plan, bautizado como el «New Deal», y destinado a revitalizar la economía. Para enfrentarse con la quiebra de 4.600 bancos, FDR decretó unas vacaciones para el sector bancario e hizo que los auditores federales estudiasen los libros de todos, para averiguar cuáles de ellos llegarían a reabrir sus puertas. Más tarde, su administración instituyó el Fondo de Garantía Federal, para proteger a bancos y a clientes de cualquier desastre financiero repentino. En sucesión rápida llegaron otras instituciones y medidas: el Cuerpo de Con-

${ }_{64}^{64}$ Richard E. Neustadt, Presidential Power and the Modern Presidents, New York: The Free Press, 1990; James David Barber, Presidential Character, Englewood Cliffs, NJ: Prentice Hall, 1972; Public Papers and Addresses of Franklin D. Roosevelt, multiple volumes; Fred I Greenstein, ed., Leadership in the Modern Presidency, Cambridge, MA: Harvard University Press, 1988; John Hart, The Presidential Branch, New York: Pergamon Press, 1987; Malcolm Shaw, ed., The Modern Presidency: From Roosevelt to Reagan, New York: Harper and Row, 1987. 
Cuerpo de Conservación Civil (CCC), que empleó a más de 3 millones de hombres jóvenes de clase trabajadora para dedicarlos a tareas de obras públicas de conservación, tales como construir carreteras, plantar árboles, o controlar inundaciones. La Administración de Ajuste Agrícola (AAA) se fundó para prevenir los excedentes agrarios limitando la producción, lo que volvió a subir los precios. La Autoridad del Valle del Tennessee (VTA) se creó para controlar las inundaciones del río Tennessee. De paso, mejoró la navegación fluvial, aumentó la economía de la región, fomentó la conservación de suelos y bosques, y proporcionó a siete estados una fuente de electricidad de bajo coste. La Administración Federal de Lucha contra Emergencias (FAER) se estableció a fin de aportar fondos a los estados para que éstos pusiesen en marcha proyectos de ayuda y de obras públicas a nivel local, destinados a aliviar la pobreza. Se aprobó una Ley de Recuperación de la Industria Nacional (NIRA), la cual creaba una Administración de Obras Públicas, destinada a conceder masivas ayudas con el fin de que estados y ciudades financiasen grandes proyectos de construcción tales como autopistas, presas, alcantarillados o edificios públicos. Aunque muchos de estos proyectos iniciales obtuvieron el éxito, al ser contestados ante los jueces, el Tribunal Supremo los declaró inconstitucionales. ${ }^{65}$

El nivel de actividad durante el segundo año de su presidencia no fue menos impresionante. Así, se creó la Comisión del Mercado de Valores en 1934 a fin de corregir los abusos que habían culminado en el desplome de la Bolsa en 1929. Se aprobó la Ley Nacional de Vivienda, por la cual nacieron la Administración Federal de la Vivienda, la Asociación Federal Hipotecaria Nacional y la Sociedad Federal de Garantía de Ahorros y Créditos, todo lo cual puso de nuevo en pie a los bancos y a la industria de la construcción. En 1935, continuó este asalto legislativo a la Depresión, con el programa de Electrificación Rural y con la Ley Wagner, que establecía la Junta Nacional de Relaciones Laborales, dando a los trabajadores el derecho a organizarse y formar sindicatos, así como a negociar de forma colectiva. También se fundó la Administración para el Progreso de las Obras, de nuevo como un gigantesco proyecto de obras públicas financiadas por el Estado. Aunque fue objeto de críticas, la WPA permitió la construcción de 125.000 edificios públicos, 650.000 millas de carreteras, y 75.000 puentes, además de muchas otras infraestructuras. Más importante, más controvertida, y más costosa a largo plazo, resultó la Ley de Seguridad Social que Roosevelt firmó dando así nacimiento al Sistema de Seguridad Social, un fondo de pensiones del Estado para todos los americanos que funciona aún hoy. Finalmente, en 1939 Roosevelt promulgó la Ley de Normas Equitativas del Trabajo, la cual institucionalizaba la semana laboral de cuarenta horas, un salario mínimo para todos los trabajadores, y prohibía el trabajo infantil en el comercio interestatal.

${ }^{65}$ Este fue el caso de la AAA en 1936 y de la NIRA en 1935. 
En relaciones exteriores, Roosevelt se vio atado por las tendencias aislacionistas que prevalecieron en los EE.UU. durante la década de 1930-40. Vio la guerra que se avecinaba, sin embargo, y emprendió su política de «Buena Vecindad", destinada a mejorar las relaciones de EE.UU. con América Latina. El sentimiento aislacionista norteamericano no cambió hasta que cayó Francia en 1940 y Hitler comenzó la Batalla de Inglaterra. Roosevelt se encontraba hacia el final de su segundo mandato, antes de decidirse a ser de nuevo candidato para un tercero. Resultó victorioso, y en este tercer mandato acercó al país a la guerra al aprobar la Ley de Préstamos y Arriendos, la cual suministró a los aliados equipos militares y otros abastecimientos por valor de 50 mil millones de dólares entre 1941 y 1946. Roosevelt hubiera querido intensificar el papel de su país en la guerra, pero carecía de un motivo que lo propiciase, hasta que el 7 de diciembre de 1941, Japón atacó la base naval norteamericana en Pearl Harbor, Hawaii. Roosevelt pidió al Congreso una declaración de guerra contra Japón y la obtuvo al día siguiente. La Alemania Nazi por su parte declaró la guerra a los Estados Unidos poco después, quedando así el país plenamente implicado en la Segunda Guerra Mundial.

La guerra y la consiguiente necesidad de una toma de decisiones inmediata le proporcionó a Roosevelt una gran cantidad de poderes o competencias implícitas, igual que lo había hecho la Gran Depresión. El 7 de septiembre de 1942, Día del Trabajo en EE.UU., hizo expresión del papel que pretendía jugar en la dirección de su país en tiempo de guerra:

En el caso de que el Congreso no actuara o no lo hiciera de la forma adecuada, yo aceptaré toda la responsabilidad y actuaré ...

El Presidente debe, en virtud de la Constitución y de las leyes del Congreso, tomar las medidas necesarias para evitar un desastre que interfiera con la buena marcha de la guerra ...

El pueblo americano puede estar seguro de que usaré mis competencias con pleno sentido de la responsabilidad hacia la Constitución y hacia mi país. El pueblo americano también puede estar seguro de que no dudaré en utilizar cada facultad que me ha sido otorgada hasta conseguir la derrota de nuestros enemigos en cualquier parte del mundo en donde nuestra seguridad demande dicha derrota.

Una vez ganada la guerra, los poderes puestos a mi disposición revertirán automáticamente en el pueblo, al cual pertenecen. ${ }^{66}$

Dos aspectos quedan claros en esta retórica de Roosevelt: su determinación y coraje para asumir poderes y responsabilidades extraordinarios, y su apelación obvia al pueblo de su país, cuyos derechos asegura haber tomado prestados, de forma temporal, a fin de ejercer ese poder. Esta es la autoridad presidencial.

${ }^{66}$ Genovese, The Power of the American Presidency, 135. 
Gracias a ella, Roosevelt fue capaz de poner en vigor rígidos controles de precios y de salarios, destinar miles de millones de dólares para el esfuerzo de la guerra, reclutar a millones de hombres para el combate, imponer la censura y, en el lado negativo de la balanza, ordenar el internamiento de más de 100.000 norteamericanos de origen japonés durante toda la guerra, como protección frente a supuestas amenazas a la seguridad. Nunca antes o después, en la historia del país, ha detentado un solo hombre tanto poder.

En cuanto al programa de política exterior de FDR, consistió en asegurar la victoria para los EE.UU. y sus aliados en la Segunda Guerra Mundial, una victoria obviamente consistente con los intereses de EE.UU. Quiso también asegurar una paz duradera de acuerdo con los intereses de este país. A tal fin, Roosevelt realizó numerosos viajes para reuniones en la cumbre con sus aliados en la guerra, en especial Gran Bretaña y la Unión Soviética. Incluso después de que el conflicto hubiese virado claramente a favor de los aliados, en 1943, Roosevelt no quiso dejar que otra persona en el cargo viese terminar la guerra y negociase la paz. Por ello se presentó candidato y ganó una cuarta victoria que no tenía precedentes en la historia del país, en 1944. En febrero de 1945 Roosevelt asistió a la Conferencia de Yalta, al sudoeste de la URSS, a fin de llegar a acuerdos para la postguerra con Churchill y Stalin. A su vuelta, informó al Congreso del resultado, y todavía supervisó los planes para la sesión de apertura, el 25 de abril, de una nueva organización, las Naciones Unidas, sucesora de la Sociedad de Naciones de Wilson. Sin embargo, y tras haber pasado unos días de bien merecido descanso, el 12 de abril de 1945 Franklin Delano Roosevelt falleció de una hemorragia cerebral, no pudiendo por tanto conocer el fin de la guerra y la culminación de sus planes para la paz, todo lo cual llegaría más tarde durante ese año. Al conocer las noticias, Winston Churchill, le dijo al parecer entre lágrimas al corresponsal de radio Edward R. Murrow «Algún día el mundo y la historia sabrán cuánto le deben a su presidente ». ${ }^{67}$

Desde el comienzo de su presidencia, ya en su discurso inaugural del 4 de marzo de 1933, FDR dio a conocer tanto al Congreso como al público que tenía planes de ser un presidente activo, enérgico, y expansivo:

En primer lugar pues, déjenme comunicarles mi firme creencia de que el único miedo que debemos tener es al propio miedo - a ese terror innombrable, irracional e injustificado, que paraliza los esfuerzos que necesitamos realizar para convertir la retirada en avance.

En principio, cabe esperar que el equilibrio normal de autoridades de ejecutivo y de legislativo sea plenamente adecuado para afrontar las tareas sin precedentes que tenemos ante nosotros. Pero pudiera suceder que una necesidad sin precedentes de actuar rápidamente nos exija apartarnos temporalmente de ese

${ }^{67}$ Ridings and Mclver, Rating the Presidents, 205. 
balance habitual en el procedimiento público. Estoy preparado en virtud de mis deberes constitucionales para recomendar medidas acordes con lo que una nación golpeada en medio de un mundo golpeado pueda requerir. Intentaré dentro de mi autoridad constitucional que tales medidas, o aquellas otras que el Congreso pueda decidir basándose en su sabiduría y experiencia, se adopten de forma rápida. Pero si el Congreso fracasara en alguno de estos dos caminos, y si la emergencia nacional siguiera siendo crítica, no eludiré entonces el curso claro del deber que se presentará ante mí. Solicitaré del Congreso que me conceda el único instrumento restante par atajar la crisis - amplios poderes del ejecutivo para declarar la guerra a la situación de emergencia, tan amplios de hecho como se me concederían si fuéramos invadidos por un enemigo extranjero. ${ }^{68}$

El discurso de FDR dejaba lo suficientemente claro al Congreso y al pueblo que iba a obrar como un líder. Desde el inicio su presidencia pretendió pues demostrar a la gente que estaba al mando del país, al tanto de sus problemas, y que pensaba aportarle soluciones inmediatas y definitivas en todo el alcance de su poder, por vía de la autoridad presidencial que en su opinión la victoria en la elección le había otorgado. Forjó una relación con el pueblo americano, a lo largo de su estancia de casi trece años en el cargo, que fue personal, transparente, informal, y a la vez firme y enérgica.

FDR fue el primer presidente de EE.UU. en hacer uso de los nuevos medios de comunicación de masas en sus apelaciones al pueblo americano. Su presidencia fue notable por sus apariciones en la serie de boletines informativos cinematográficos conocidos como «Newsreels». Era fotogénico, pese a su discapacidad, y sus ademanes sencillos y aristocráticos a la vez ante la cámara parecían inspirar en la gente una confianza en su liderazgo. Proyectaba esa autoridad presidencial, lo que a su vez contribuía a acrecentarla. Muchos de los discursos de FDR se difundían por la radio. Aunque ya Calvin Coolidge había sido el primer presidente en usar la radio, FDR fue el primero en reconocer su enorme potencial para alcanzar a todo el público de los EE.UU. y en emplearla de esta manera. Sus "charlas junto al fuego" en las que se dirigía informalmente al pueblo americano a través de la radio, se hicieron legendarias. Transmitieron esperanzas a los norteamericanos, algo de lo que estaban muy necesitados durante la Gran Depresión, lo cual tenía al país atenazado hasta su llegada al cargo. Estos discursos conectaban al presidente directamente con el pueblo hasta un grado nunca antes imaginado.

La relación de FDR con el resto del Estado resultó algo más problemática. Siguiendo el mismo espíritu que Jackson, Lincoln, T. Roosevelt, y Wilson, tuvo una relación complicada con el Congreso, dado que a menudo ignoraba la autoridad del legislativo a la hora de diseñar sus políticas. La gravedad de la Depresión y de la Segunda Guerra Mundial consiguió que Roosevelt pudiera usar de sus poderes de emergencia y sus órdenes ejecutivas o de-

\footnotetext{
${ }^{68}$ Bennett, The American Presidency 1945-2000, 18.
} 
cretos para actuar de forma expeditiva, expandiendo el poder del Presidente y empujando al Congreso para que actuase también de forma rápida, sin largas deliberaciones. Por supuesto, si el Congreso no obraba con la celeridad requerida, FDR no dudaba en «puentearle» por la vía del decreto del ejecutivo. De esta manera, a menudo trató al Congreso como si estuviera ahí simplemente para estampar su sello sobre la legislación que él personalmente había promulgado.

Las relaciones de FDR con la rama judicial del Estado fueron también problemáticas, por lo menos en sus inicios. Como ya dijimos, El Tribunal Supremo declaró incompatibles con la Constitución algunas de sus primeras iniciativas. Ello molestó a FDR hasta tal punto que, después de su nueva victoria electoral en 1936, intentó forzar al Congreso para que introdujera un plan de reorganización del poder judicial, el cual le hubiera permitido añadir al Tribunal Supremo un número suficiente de nuevos magistrados como para vencer en las votaciones a los jueces conservadores y así aprobar sus iniciativas legislativas. Aunque su plan suscitó el rechazo de las Cámaras y fue derrotado, tuvo el curioso resultado de volver al Tribunal Supremo más receptivo a las iniciativas del Presidente. Después de 1937, el Alto Tribunal comenzó a aprobar las medidas de Roosevelt con escasa o nula oposición. De esta forma, se vio que a la larga y como ha sucedido otras veces en la historia de los EE.UU., el Tribunal no puede alzarse frontalmente contra un determinado presidente. El peligro que trae consigo esta rebaja del sistema de equilibrios y contrapoderes en que se basa el sistema político norteamericano, se hizo patente cuando el Tribunal Supremo denegó los recursos de amparo en contra de la política de FDR de internamiento de los japoneses-americanos, pese a constituir una flagrante violación de sus derechos civiles como ciudadanos de la nación.

El impacto que la presidencia de Franklin Delano Roosevelt tuvo sobre la institución es inconmensurable. Llegó al cargo encontrándose, probablemente, con el mayor desafío al que jamás tuvo que hacer frente ningún presidente. La Gran Depresión y la Segunda Guerra Mundial exigían un liderazgo fuerte si se quería que el país emergiera con éxito de esa doble situación de crisis. FDR fue capaz de estar a la altura de ese desafío, merced a esa visión suya de ampliación más extensa del poder presidencial desde la era de Lincoln. Sin embargo, a diferencia de este ilustre predecesor, FDR se tuvo que enfrentar a graves problemas nacionales e internacionales en un mundo en el que se contaba con que EE.UU. se pusiera como líder al frente. Se acabaron ya los días en que los presidentes sólo estaban para administrar y para persuadir. Roosevelt se vio obligado a utilizar su puesto para dirigir, tal y como él mismo escribió:

La Presidencia no es un mero puesto administrativo. Esa sería una visión empequeñecida. Es sobre todo un puesto de liderazgo moral.

Todos nuestros grandes presidentes fueron dirigentes de la opinión en épocas en las que las ideas históricas en la vida de la nación tenían que ser clarificadas. 
Washington personificó la idea de una Unión Federal; Jefferson prácticamente originó el sistema de partidos tal y como hoy lo conocemos, al oponer la teoría democrática con el republicanismo de Hamilton. Esta teoría fue reafirmada por Jackson.

Lincoln consiguió que algunos grandes principios de nuestro gobierno quedaran fuera de toda duda para siempre. Cleveland, al asumir el cargo tras una era de corrupción política, fue ejemplo de honradez. Theodore Roosevelt y Woodrow Wilson fueron ambos autoridades morales, cada uno a su manera y para su tiempo, usando la Presidencia como un púlpito.

En eso consiste este puesto - en una soberbia oportunidad para retomar, aplicándolas a unas condiciones nuevas, las simples reglas de la conducta humana a las cuales siempre acabamos recurriendo. Sin un liderazgo alerta y sensible a los cambios, ... perdemos el camino. ${ }^{69}$

FDR no podía permitir a los norteamericanos ni a su país que perdiesen el camino. Se encargó de dirigir la promulgación de un número extraordinario de leyes de gran importancia y que abrieron nuevos caminos. Expandió el poder de la Presidencia hasta tal punto, que ésta ya nunca podría volver a ser desempeñada bajo el modelo Federalista o tradicional. Fue él quien consolidó la Presidencia en su forma contemporánea, y lo hizo sobre bases tan firmes, que todos los presidentes posteriores han tratado de emularle en alguna ocasión. Todos los presidentes de la era post-FDR, por ejemplo, han hecho uso de la radiodifusión de sus discursos para informar y conectarse con el pueblo americano, tal y como FDR hiciera de forma pionera con sus "charlas junto al fuego». Ningún presidente después de él ha desperdiciado la oportunidad de emplear las situaciones de emergencia nacional para tratar de ampliar sus propias competencias. Aunque el Congreso ha disfrutado de algunos periodos breves de capacidad de obstrucción, ya nunca ha conseguido volver a tomar las riendas del Estado ni dominar al ejecutivo como lo hiciera en la era anterior a FDR. En verdad, una muestra más de la influencia de FDR sobre la Presidencia de los EE.UU., lo constituye la aprobación de la 22. ${ }^{a}$ enmienda a la Constitución en 1947, por medio de la cual la estancia de un presidente en el cargo quedó formalmente limitada para siempre a dos mandatos.

\section{PRESIDENTES Y PARLAMENTOS: EL SISTEMA PRESIDENCIAL NORTEAMERICANO COMO MODELO POLÍTICO}

He expuesto en líneas generales el origen, la historia, la función y la evolución de la Presidencia norteamericana, pero sólo en referencia a su contexto específico. Desde que se disolvió la Unión Soviética, con la aparente victoria del capitalismo global y de los sistemas políticos representativos, los teóricos políticos han revivido la polémica acerca de los méritos de los siste-

${ }^{69}$ Genoves, The Power of the American Presidency, 138. 
mas presidencialista versus parlamentario ${ }^{70}$. La clave del debate parece centrarse en la efectividad comparativa y la naturaleza democrática de ambos sistemas de gobierno. Estos debates se escapan del ámbito del presente trabajo. No obstante, todos los sistemas políticos representativos, incluyendo aquellos que tienen una naturaleza democrática en mayor o menor grado, generalmente caen en uno de los dos modelos citados. Mi intención en la presente sección es restringirme a defender la tesis de la aparente «inexportabilidad» del sistema presidencial norteamericano. Existe a disposición del lector interesado un abundante material bibliográfico que compara los sistemas presidencialista y parlamentario: en la discusión que sigue, hago referencia a un par de casos sacados de toda esa literatura.

Los sistemas representativos que se auto-presentan como con fundamento democrático, provienen todos del contexto del siglo XVIII con la caída de la Monarquía absoluta. Las teorías políticas avanzadas por Hobbes y por Locke fueron estudiadas y divulgadas por los filósofos de toda Europa en general, y por los de la Francia de la llustración en particular. Lo que los philosophes franceses buscaban no fue tanto un sustituto de la monarquía - pues una revolución política así pondría en peligro su propia posición social, ya que muchos de ellos provenían de la clase aristocrática- sino una disminución de la autoridad del Monarca absoluto. En esencia, querían un sistema que repartiese mejor el poder, de forma que estuviese menos sujeto a los caprichos y devaneos de una sola persona. Su modelo para esta nueva concepción del gobierno político fue la monarquía constitucional británica (recordemos que los colonos norteamericanos todavía no habian llevado a cabo su independencia), tal y como ésta había surgido tras la Revolución Gloriosa de 1688. Vieron en el modelo inglés una monarquía controlada por un órgano legislativo que podía atajar cualquier comportamiento arbitrario por parte de la Corona, lo cual les parecía justo la cura que necesitaban los males de la monarquía francesa. Francia tenía una serie de órganos políticos representativos, incluido uno más grande, de representación de ámbito nacional, los Estados Generales, los cuales podían servir como modelos para el desarrollo de un sistema parlamentario de estilo inglés. Esta abundancia de órganos de representación era de hecho una constante en casi todo el resto de Europa en aquella época.

Aun cuando los orígenes de los sistemas presidenciales modernos es un poco más difícil de trazar, también se les puede buscar en el contexto de declive de la monarquía absoluta en la Francia ilustrada. Charles Secondat, a quien conocemos como Barón de Montesquieu, publicó su principal tratado socio-político, El espíritu de las leyes, en 1748. El espíritu de las leyes introdujo un nuevo concepto en la teoría política, el de la separación o división de

\footnotetext{
70 Véase Lijphart, Parliamentary versus Presidential Government y Von Mettenheim, Presidential Institutions and Democratic Politics.
} 
poderes ${ }^{71}$. Montesquieu comprendió que el poder político confería una autoridad, y que combinar ambos en manos de un solo individuo conduciría inevitablemente al abuso. Por eso teorizó que «Para prevenir este abuso, resulta necesario de la propia naturaleza de las cosas que el poder controle al poder ${ }^{72}$. En esta afirmación, Montesquieu capturó la esencia del gobierno efectivo, al tiempo que describía un equilibrio crudo entre las tres ramas del Estado por el poder que cada una debería tener a fin de poder controlar el de las otras. Montesquieu no era un republicano, pero su teoría política expresó tanto la esencia del republicanismo representativo que más tarde sería puesto en práctica en los EE.UU., como el primero de los principios que iban a regir su sistema de gobierno. El Estado norteamericano es separacionista hasta su médula. Funciona del modo en que lo hace porque cada una de las tres ramas del Estado ostenta unos poderes independientes y mantiene identidades separadas ${ }^{73}$. Podríamos decir, a la manera de Montesquieu, que las tres ramas se encuentran controladas. Los Padres de la Constitución de EE.UU. conocían bien la obra de Montesquieu, y se vieron muy influidos por su concepción de los poderes separados - una idea que combinaron con las nociones de Locke acerca de las funciones del legislativo y del ejecutivo. De ahí que no sorprenda que el Estado que los constituyentes de EE.UU. construyeron incorporase elementos importantes de las teorías políticas radicales de Locke y de Montesquieu.

Pero ¿qué hay de la exportabilidad o no de la Presidencia norteamericana como modelo de gobierno presidencialista a otros países? Es interesante constatar que el sistema presidencialista de los EE.UU. no ha podido ser trasplantado con éxito a ningún otro país ${ }^{74}$. De hecho, el presidencialismo en general ha tenido una historia bastante accidentada a la hora de su implantación en otros países aparte de EE.UU. y de Francia. Lo que es más, si bien el sistema presidencial ha funcionado adecuadamente en los EE.UU. desde 1789, el mismo sistema en Francia data sólo de 1958. Por contra, los Estados de tipo parlamentario prevalecen en la mayor parte del mundo siendo, de lejos, mucho más longevos y estables que los de estilo presidencialista ${ }^{75}$. Tan magros resultados para un sistema político como el presidencial norteamericano por supuesto provoca la pregunta de por qué ello es así. ¿Qué es lo que sucede con el sistema presidencialista de EE.UU. que evita su duplicación con éxito en otros lugares? ¿Existe algún elemento concreto en el modelo americano que le convierta en inexportable?

\footnotetext{
${ }^{71}$ Véase Montesquieu, The Spirit of the Laws, Trad. Thomas Nugent, con introducción de Franz Neuman, New York: Hafner Publishing Co., 1949, 149-162.

${ }_{72}$ lbid., 150.

${ }^{73}$ Véase Charles O. Jones, «The American Presidency: A Separationist Perspective» en Mettenheim, Presidential Institutions, 19-44.

${ }^{74}$ Véase Fred W. Riggs, «Presidentialism: A Problematic Regime Type», en Lijphart, Parliamentary versus Presidential Government, 217-220.

${ }^{75}$ lbid., 218-220.
} 
Me gustaría ofrecer algunas explicaciones a la falta de exportabilidad del sistema presidencial norteamericano. En primer lugar, debemos volver al contexto histórico de los orígenes del modelo norteamericano de Presidencia que ya discutimos con anterioridad. Dicho modelo se construyó en un clima histórico social y político muy particular como era el de los EE.UU. de finales del siglo XVIII. El país acababa de ganar en una guerra su propia independencia, y luchaba ahora por hallar un marco de gobierno apropiado para la federación de estados que componía el país. El liderazgo político norteamericano se fundó sobre las ideas políticas de la llustración, en particular, las teorias de los ilustrados acerca del legislativo opuesto al ejecutivo, poderes del Estado separados pero equilibrados, soberanía limitada frente a soberanía popular, y republicanismo constitucional frente a democracia constitucional. Estas ideas de la llustración estaban en boga y eran bien conocidas por los Padres de la Constitución de los EE.UU. justo cuando éstos pugnaban por fundar una república representativa que garantizase los derechos de propiedad a la vez que proporcionase una aceptable libertad individual, sin sacrificar el orden social y político. Para cuando otros estados, sobre todo las repúblicas latinoamericanas, intentaron poner en pie sistemas similares al norteamericano, las ideas ilustradas ya habían perdido parte de su validez, y las circunstancias de EE.UU. no pudieron repetirse en estos otros países.

Otra fuente de dificultad a la hora de tratar de aplicar un sistema presidencialista de estilo norteamericano se refiere a la estructura política de este Estado, de nuevo fruto del contexto histórico. El Estado norteamericano opera, con mayor o menor efectividad, porque ninguna rama del sistema tripartito puede dominar con autoridad absoluta a las otras. Los constituyentes establecieron un sistema de gobierno con tres entes separados y casi iguales -legislativo, ejecutivo, y judicial-, proporcionándoles la capacidad de controlarse mutuamente. Así, el legislativo (el Congreso) tiene competencias de aprobación que sirven como control del poder ejecutivo. El ejecutivo tiene competencias de denegación (el veto del Presidente) que controlan el poder del legislativo. El judicial controla la legalidad, en términos de adecuación a la Constitución, tanto del legislativo como del ejecutivo, siendo el único órgano de interpretación de la Constitución. Por tanto, y conforme a la teoría política de los ilustrados, el Estado norteamericano consiste en tres entes independientes y de poderes equilibrados que juntos, en una suerte de dependencia recíproca, se dedican a la tarea común de gobernar al pueblo de los EE.UU.. El Congreso, al ser directamente elegido por el pueblo, puede afirmar que es el representante de las preocupaciones locales y particulares de los norteamericanos. El Presidente puede asegurar que es el representante de todos los ciudadanos, en general, porque su cargo es el único en todo el Estado elegido por la totalidad del pueblo americano. En cualquier caso, las ramas legislativa y ejecutiva dependen entre sí recíprocamente, y los fundamentos populares del gobierno de EE.UU. se ponen de manifiesto por la capacidad, tanto del Presidente como del Congreso, de reclamar su autoridad como representantes legítimos del pueblo americano. 
Las peculiaridades del federalismo norteamericano aportan otro elemento acerca de la dificultad de transplantar el modelo presidencial de EE.UU.. A diferencia de Brasil, el federalismo norteamericano está equilibrado, sin pecar de excesivamente fuerte ni de decididamente débil ${ }^{76}$. Los cincuenta estados tienen abundantes competencias legales, financieras y sociales; pero cuando haya un conflicto de normas, la ley estatal estará casi siempre subordinada a la ley nacional o federal. De nuevo refiriéndonos al contexto histórico de la creación de los EE.UU., existió un federalismo muy fuerte bajo los Artículos de la Confederación, demostrando su ineficacia en términos de organizar y de armonizar una acción común dirigida. Los constituyentes vieron que los EE.UU. no podían continuar sin una revisión de los derechos en manos de los estados. Intentaron resolver esta situación creando un gobierno central más fuerte, pero sin usurpar todos los derechos estatales. En el sistema bicameral de Cámara de Representantes y Senado, los miembros del Congreso representan tanto al pueblo como a los estados, teniendo pues los estados representantes y abogados de sus derechos.

La Constitución de EE.UU. y la fe que los norteamericanos sienten por este documento, revelan otro elemento que dificulta la duplicación del sistema de este país en otros lugares. La Constitución, escrita en 1787-1788, sigue siendo el texto que describe la ley del país y la manera en que debe operar el Estado norteamericano. Encierra así mismo los ideales del pueblo americano en forma escrita. Esto, sin embargo, no convierte a la Constitución de EE.UU. en algo distinto. Lo que hace de la Constitución de EE.UU. un documento único es el sentimiento que despierta en el pueblo norteamericano. No es ninguna exageración afirmar que los norteamericanos sienten veneración por su Constitución. Aunque la Constitución haya sido enmenda$\mathrm{da}$, proceso bastante difícil por lo demás ya que requiere que dos tercios de los estados ratifiquen una enmienda para que se convierta en ley, el texto en sí nunca ha sido reescrito ni reemplazado. A título de comparación, Francia ha conocido al menos media docena de constituciones desde la promulgación de la primera en 1791. España ha tenido al menos ocho entre la redacción de la primera, en 1812, y su Constitución más reciente, que data de $1978^{77}$. Los americanos, por contraste, resultan extremadamente conservadores y respetuosos con un documento que se escribió en el siglo XVIII, pero del cual se espera flexibilidad' suficiente para poder confrontar los problemas del siglo XXI.

Lo que ello nos revela es la naturaleza excepcional del caso norteamericano. Su presidencialismo no es exportable. En realidad, cabría defender

\footnotetext{
${ }^{76}$ Para una descripción del federalismo en Brasil y los retos que presenta para un gobierno nacional efectivo, véase Scott Mainwaring, «Presidentialism in Brazil,», The Latin American Program, Woodrow Wilson International Center for Scholars, 27-29.

${ }^{77}$ En ambos casos, para Francia y España, sólo contamos las constituciones que llegaron a ser promulgadas, y no las que se quedaron en simples proyectos.
} 
que ningún sistema presidencial es exportable porque, para ser efectivo, tal sistema debe ser derivación del contexto cultural, social, político e histórico del país y de la gente para el cual se crea. Por ejemplo, el actual sistema político francés, al que algunos estudiosos califican de semi-presidencialista y otros de presidencial híbrido, está ligado inextricablemente al contexto histórico en el que el Estado representativo francés ha evolucionado desde el año 1789 hasta nuestros días ${ }^{78}$. Desde la Revolución hasta hoy, el péndulo político en Francia ha venido oscilando entre regímenes autoritarios fuertes, como los de Napoleón Bonaparte, Luis Napoleón, Mariscal Petain y Charles DeGaulle, y regímenes democráticos de corte parlamentario como fueron la Segunda y la Tercera República, y la Quinta República de nuestros días. El contexto histórico social, político, y cultural de ese país es imposible de transplantar, igual que el de los EE.UU..

Finalmente, el modelo de Estado presidencial norteamericano requiere de un teórico equilibrio de poderes que resulta difícil de alcanzar en la práctica. Sin esa mutua dependencia que ofrece el presidencialismo norteamericano, los sistemas políticos tienen la tendencia a caer en uno de dos posibles fallos importantes. Uno, el ejecutivo está demasiado debilitado, de forma que el Gobierno se convierte esencialmente en parlamentario, asumiendo el legislativo el poder y la autoridad que deberían residir en el ejecutivo. Si además unimos a ello la existencia de un robusto federalismo, entonces la descentralización del poder hace el Gobierno nacional efectivo prácticamente imposible. Dos, el ejecutivo puede tender a reforzarse demasiado, y el Estado deriva hacia el autoritarismo o la dictadura. En ese caso, la rama legislativa queda virtualmente despojada de su poder de acción, y o bien se disuelve o se convierte en mero órgano de refrendo, que automáticamente aprueba los mandatos del ejecutivo. Por desgracia, la naturaleza del sistema presidencial parece contener dentro de sí estas dos semillas, especialmente si deja de haber el suficiente entendimiento entre los poderes legislativo y ejecutivo en cuanto a independencia institucional, dependencia recíproca, y dedicación común al Gobierno. Además, el marco constitucional de ese régimen debe diseñar claramente un sistema capaz de «controlar poder con poder". Si el sistema presidencialista funciona en EE.UU. se debe en gran medida a la comprensión a priori por los constituyentes de esos principios políticos básicos, extraídos de Locke y de Montesquieu.

${ }^{78}$ Véanse Maurice Duverger, «A New Political System Model: Semi-Presidential Government», en Lijphart, Parliamentary versus Presidential Government, $142-149$ y, John T.S. Keeler and Martin A. Schain, «Institutions, Political Poker, and Regime Evolution in France», en von Mettenheim, Presidential Institution and Democratic Politics, 84-105. 


\section{CONCLUSIÓN}

La Presidencia norteamericana, y el sistema político en el que esta institución se encuadra, está ligada de forma unívoca al contexto político, social y cultural de los EE.UU. Hemos contemplado cuán exigente es el cargo de Presidente. Hemos visto sus múltiples funciones. Hemos conocido el escepticismo de aquéllos que lo crearon, y analizado el sistema estatal federal que soporta y a la vez controla el poder del Presidente. Y hemos abordado el tema de la «inexportabilidad» del modelo presidencial norteamericano. En última instancia, la Presidencia será tan eficaz como lo sean las personas que ocupen el puesto. Cada vez más, se está convirtiendo en una tarea ímproba, que despierta expectativas mucho más elevadas de lo que el cargo en la vida real puede satisfacer.

En cierto sentido, la Presidencia parece haberse quedado obsoleta. Los sistemas parlamentarios parecen más capaces de captar y de coaligar un espectro más amplio de la opinión pública política que el viejo y contestado sistema bipartidista norteamericano. De hecho, cabría argumentar que el sistema ha fallado, puesto que el actual ocupante de la residencia del 1600 de Pennsylvania Avenue no es el ganador de la votación del año 2000. Es cuando menos problemático que el hermano del Presidente fuera gobernador del estado que decidió las elecciones, y precisamente en donde tuvieron lugar las mayores «irregularidades". Es turbador que el Tribunal Supremo validara unas elecciones tan rodeadas de posibles fraudes. Finalmente, causa verdadera preocupación que el pueblo americano hiciera tan poco ante tan obvia burla a sus derechos constitucionales y a su sistema electoral.

Sin duda, el sistema político de EE.UU. deberá sufrir reformas si se pretende que siga siendo representativo de los intereses populares. Tendrá que ser ampliado, en términos de otros partidos políticos, y de responsabilidad frente al deseo político del pueblo americano. Parece que con cada nueva elección, los partidos demócrata y republicano se parecen cada vez más. Se da una extensa antipatía hacia el acto del voto en los EE.UU. Muy pocas elecciones presidenciales consiguen una participación mayor del $60 \%$ del total de los potenciales votantes, lo cual resulta muy descorazonador. Hay muchas maneras en que la situación podría remediarse, incluyendo dar apoyo federal a candidatos a la Presidencia por un tercer y un cuarto partido, instituir la representación proporcional en el Congreso, reformar la normativa sobre financiación de los partidos más a fondo, y deshacerse de una vez del Colegio Electoral, que decide quién gana la presidencia. Todo ello necesitaría que un presidente u otro político, decidido y realmente comprometido con los cambios, liderase el esfuerzo por realizar tales reformas. Hasta que tenga lugar tal evolución del sistema, las expectativas del pueblo americano seguirán recayendo en aquel cargo que supuestamente le representa en su conjunto, es decir, sobre su presidente. Es también una certeza que los futuros ocupantes de este puesto, al igual que han hecho sus predecesores 
desde George Washington a George W. Bush, continuarán dando forma, expandiendo y redefiniendo la tarea de ser Presidente, mientras se esfuerzan por colmar las responsabilidades y la expectativa de llegar a representar a la totalidad de los ciudadanos norteamericanos. 